\title{
THE BROOKHAVEN NATIONAL LABORATORY PERFLUOROCARBON TRACER TECHNOLOGY: A PROVEN AND COST-EFFECTIVE METHOD TO VERIFY INTEGRITY AND MONITOR LONG-TERM PERFORMANCE OF WALLS, FLOORS, CAPS, AND COVER SYSTEMS
}

John Heiser and Terry Sullivan

March 11,2002

\section{BRODKHBVEN \\ NATIONAL LABORATORY}

\begin{abstract}
Environmental Sciences Department
Brookhaven National Laboratory

Brookhaven Science Associates

Upton, Long Island New York 11973
\end{abstract}

Under Contract No. DE-AC02-98CH10886 with the

UNITED STATES DEPARTMENT OF ENERGY 


\section{DISCLAIMER}

This report was prepared as an account of work sponsored by an agency of the United States Government. Neither the United State Government nor any agency thereof, nor any of their employees, not any of their contractors, subcontractors, or their employees, makes any warranty, express or implied, or assumes any legal liability or responsibility for the accuracy, completeness, or usefulness of any information, apparatus, product, or process disclosed, or represents that its use would not infringe privately owned rights. Reference herein to any specific commercial product, process, or service by trade name, trademark, manufacturer, or otherwise, does not necessarily constitute or imply its endorsement, recommendation, or favoring by the United States Government or any agency, contractor, or subcontractor thereof. The views and opinions of authors expressed herein do not necessarily state or reflect those of the United States Government or any agency, contractor or subcontractor thereof. 


\title{
The Brookhaven National Laboratory Perfluorocarbon Tracer Technology: A Proven and Cost-Effective Method to Verify Integrity and Monitor Long-Term Performance of Walls, Floors, Caps, and Cover Systems
}

John Heiser and Terry Sullivan

March 11, 2002

\author{
Environmental Sciences Department \\ Brookhaven National Laboratory \\ Brookhaven Science Associates \\ Upton, Long Island New York 11973
}

Under Contract No. DE-AC02-98CH10886 with the

UNITED STATES DEPARTMENT OF ENERGY

*This work was performed under the auspices of the U.S. Department of Energy. 



\section{Executive Summary}

For the past few decades, Brookhaven National Laboratory (BNL) researchers have been investigating various aspects of both surface covers and subsurface barriers. In the early 1990's when BNL became actively involved in the U.S. Department of Energy Office of Science and Technology (DOE OST) research programs for subsurface barriers, it became increasingly apparent that the development of verification and monitoring technologies was lagging, while development of improved barrier materials and installation methods was being vigorously pursued.

Subsequently, BNL developed a uniquely capable, barrier verification and performance monitoring technology that uses a suite of gaseous perfluorocarbon compounds to detect holes, flaws, and breaches in a barrier and to measure performance characteristics of the barrier. Unlike geophysical methods, Perfluorocarbon Tracers (PFTs) can be utilized under a very wide range of conditions including waste sites with large quantities of metals.

PFT technology is the most sensitive of all non-radioactive tracer technologies and concentrations in the range of parts per quadrillion $\left(1\right.$ in $\left.10^{15}\right)$ are routinely measured. This allows detection of very small breaches in the barrier and/or use of very small quantities of tracer.

Leaks are located by injecting a series of tracers on one side of a barrier and then monitoring for those tracers on the other side. The injection and monitoring of the tracers is accomplished using conventional, low-cost monitoring methods, such as existing vadose zone monitoring wells or multilevel monitoring ports, placed using penetrometer techniques (e.g. Geoprobe). The amount, type of tracer (speciation), and arrival times can all be used to characterize the size and location of a breach. The technology utilizes multiple tracer types that can be injected at different points along the barrier. The ability to simultaneously use multiple PFTs separates it from other gas tracer technologies. Using multiple tracers provides independent confirmation of flaw location, helps to clearly define transport pathways, and can be used for confirmatory testing (e.g., repeating the test using a new tracer). The PFT tests provide a direct measure of flaws in a barrier whereas other measurements (pressure, moisture content, temperature, subsidence) provide indirect measures that need interpretation.

The PFT technology directly supports accelerated site closure needs outlined under Thrust I as recently defined by DOE EM-1. Fernald, Rocky Flats, and all of the smaller closure sites are planning to use some form of barrier to contain contaminants. Some of these new covers are expected to maintain their performance for periods of up to 1000 years. The need for a reliable method of verification and long-term monitoring is readily apparent. The BNL PFT technology can uniquely fulfill many aspects of verification and long-term monitoring. 
Currently, containment system failures are detected by monitoring wells downstream of the waste site. Clearly this approach is inefficient, as the contaminants have already migrated from the disposal area before they are detected. Methods that indicate early cover failure (prior to contaminant release) or predict impending cover failure are needed. The BNL PFT technology can measure performance changes and integrity losses as the cover ages. This allows early detection of cover failure or pending failure so that repair or replacement can be made before contaminants leave the disposal cell.

The PFT technology can verify integrity, measure performance parameters (e.g., diffusivity), and monitor performance and integrity throughout the life of a cover. PFTs work with multi-layer systems and convoluted leak pathways, require simple equipment for analysis, and are extremely sensitive. The PFT technology, while not fully developed, has been proven in several deployments including a "hot" demonstration of subsurface barrier installation and a D\&D project at the BNL Brookhaven Graphite Research Reactor. An outline of the key successes at each of these deployments is given below.

\section{Key Successes}

\section{Hanford Demonstration (1995)}

- First deployment of PFT technology successfully demonstrated, on a proof-ofconcept level, that the technology was capable of verifying barrier integrity.

- Was able to measure barrier performance by estimating (order of magnitude) the diffusion coefficient of the cement layer of the barrier.

\section{Brookhaven Chemical Glassware Waste Pit G-11 (1996)}

- Acceptance of the PFT technology by regulators as a suitable verification tool.

- First application of PFT technology at an actual remediation site.

\section{Viscous Liquid (Colloidal Silica) Barrier (1997)}

- The PFT technology was the most successful verification tool used at the demonstration. Geophysical methods did not come close to accurately defining holes and the single tracer system from SEA, Inc. could not differentiate between spill over and leakage near the top of the barrier. Excavation of the barrier provided proof that the PFT technology accurately defined the leaks and flaws in the barrier.

- Data was very stable and provided a consistent picture throughout the one-month sampling period.

\section{Waldo Test Facility (1998)}

- The PFT technology was used to detect a total of seven flaws. This included the six engineered flaws and one non-engineered flaw at a seam between the north and east walls.

- Multiple flaws were detected on the east (three flaws) and north (two flaws) walls.

- The use of multiple tracers allowed monitoring of transport around the barrier. This permitted differentiation between tracers originating from spillover, flaws on 
the other sides of the barrier (and moving underneath or around the barrier), and flaws in seams of the barrier. This capability is lost with single tracer systems and the $\mathrm{SF}_{6}$ tracer system failed to detect the seam leakage as it could not differentiate seam leakage from overflow of tracer from the top (or from holes in the sides).

- The use of multiple tracers provided simultaneous and independent confirmation of flaw locations.

- The PFT data were used to accurately determine the relative size of the flaws in each barrier.

\section{Brookhaven Graphite Research Reactor (2001)}

- The PFT technology allowed the determination of the leak paths and relative size of the leaks in the Below Grade Ducts (BGD) without having to unearth and inspect the ducts. The information gained was used to guide the soil characterization.

- The PFT technology allowed rapid determination of the leaks from the BGD.

- Multiple tracers allowed for confirmatory data for all leaks.

- The technology was accepted by regulators as a leak-detection tool and was well received by stakeholders.

\section{Cover Verification at the Savannah River Site (SRS) Bentonite Mat Cover Test Facility (2001)}

- The proof-of-concept testing at SRS was successful. The Bentomat Test Pad represented a worst-case scenario for tracer verification of covers. The cover has a very thin soil layer overlying the hydraulic barrier. This allows barometric pumping, wind effects, and atmospheric dilution effects to be maximized.

- Three small (1 $1 / 4$ ") flaws were readily detectable. Small flaws were detected without having to increase the internal concentrations of PFTs over normally used values

- The results were repeatable day to day and were confirmed by two separate tracers.

- The use of a field-deployable gas chromatograph PFT detector was successfully demonstrated. This unit was able to analyze samples on a four-minute cycle down to levels of a few parts per trillion

The focus of the six PFT demonstrations has been on engineering aspects of the technology with the intent of finding if a flaw existed in the barrier. Work remains to be done on the scientific basis for this technology. This includes determining PFT diffusion rates through various materials (soils and barrier) as a function of moisture content, determining the effects of barometric pumping on PFT flow for cover systems, and determining wind effects on side slopes of cover systems and their impact on PFT performance. It also includes application of models to assist in the design of the monitoring system and the interpretation of the data.

For cover system/barrier verification and long-term monitoring, the PFT technology has much to offer once fully developed. The PFT technology can be fully developed in a 
relatively short time (i.e., to meet aggressive site-closure schedule needs) and promises a significant advancement over current technologies. At the request of DOE, the American Society for Mechanical Engineers (ASME) conducted a peer review of the PFT technology for cover system verification and long-term monitoring. Among their findings they stated; "Based upon the limited amount of field data collected at the DOE SRS Bentomat Cover Test Plot, it appears that the PFT technology will address the technical challenges of cover/capping system integrity verification......These results give promise that PFT monitoring technology will address future DOE cover/capping integrity verification needs and long-term monitoring requirements."

For cover system assessment, the PFT technology requires some additional development so that the PFT technology can be considered fully functional, fully developed (all capabilities utilized), and commercially viable. Development needs are discussed in Section 4 and include:

- The development of the PFT technology for cover/capping integrity verification requires additional theoretical modeling.

- Further development and field-testing of surface and/or above-ground sampling protocols for the effective use of this technology.

- Consistent protocols for the installation of the PFT technology as part of existing and new cover/capping systems need to be developed.

- A cost estimate and life-cycle assessment need to be developed. The cost analysis and commercialization needs to develop in parallel to the technology. 


\section{Table of Contents}

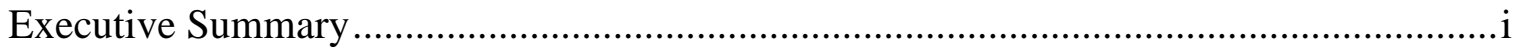

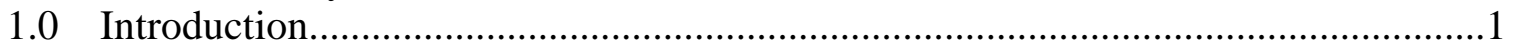

2.0 Technology Need .......................................................................................

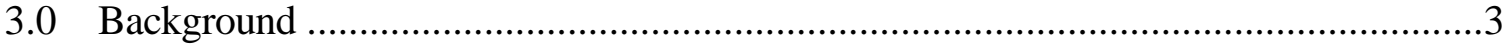

3.1 PFT Monitoring/Verification Technology Description .................................4

4.0 Advancing the PFT Technology to Meet the Needs of Closure Sites ......................6

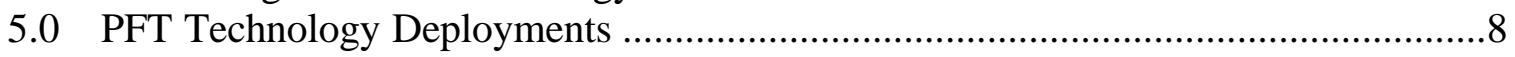

5.1 The Hanford Close-Coupled Barrier..............................................................9

5.2 Brookhaven National Laboratory Chemical Waste Pits ...............................11

5.3 Colloidal Silica (Viscous Liquid) Barrier ...................................................13

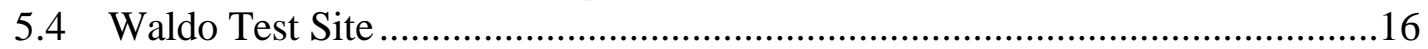

5.5 Brookhaven Graphite Research Reactor (BGRR) ....................................21

5.6 Cover Verification at the Savannah River Site Bentonite Mat Cover Test Facility ..........................................................................25

5.6.1 Additional Benefits of Using the PFT Technology for Cap and Cover Systems ............................................................30

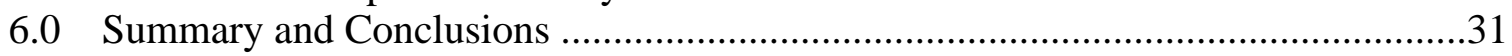

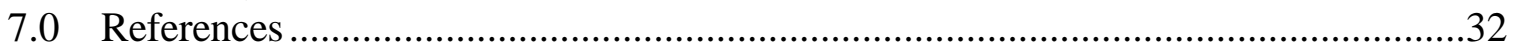




\section{List of Figures}

Figure 1. Schematic of PFT Technology with Multiple Tracers..............................5

Figure 2. Schematic of the Close-Coupled Barrier at Hanford ................................10

Figure 3. Using PFTs to Verify the Cement Layer at the Hanford Barrier...............10

Figure 4 Schematic of Barrier Installation at the BNL Chemical

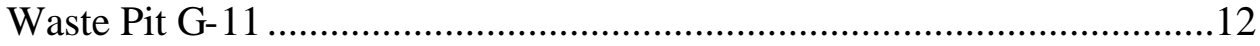

Figure $5 \quad$ Color Contours for the Tracer oc-PDCH at the East Wall.......................15

Figure 6 Color Contours for the Tracer PMCH at the Slant Wall...........................15

Figure 7 Excavation of the CS Barrier Showing a Major Flaw in the Slant Wall ...16

Figure $8 \quad$ Schematic of the Waldo Test Barrier .....................................................17

Figure 9 PMCH Contours for the West Wall at the Waldo Test Facility Days 5 to 9 ............................................................................................. 18

Figure 10 PDCB Contours for the West Wall at the Waldo Test Facility -

Days 1 to 14 ..............................................................................20

Figure 11 Schematic of the BGRR Showing the Below Grade Ducts ......................22

Figure 12 Concentration Profile for the Tracer PMCP at the South Duct ................24

Figure 13 Concentration Profile for the Tracer oPDCH at the North Duct ..............25

Figure 14 Schematic of Brookhaven PFT Technology for Verification and Long-term Monitoring of Cap and Cover Systems................................27

Figure 15 Tracer Concentrations at the Bentomat Test Cover on

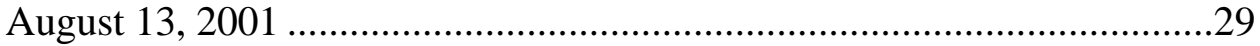

Figure 16 PMCH Concentrations at the Bentomat Test Cover on

August 16, 2001 ......................................................................... 30

\section{List of Tables}

Table 1. Chemical Acronym, Name, and Formula for PFT Tracers.......................6 


\subsection{Introduction}

For the past few decades, Brookhaven National Laboratory (BNL) researchers have been investigating various aspects of both surface covers and subsurface barriers. This research has spanned design, materials, installation, contaminant mobility, infiltration, longevity, durability, verification, and monitoring and has been funded by the U.S. Department of Energy (DOE), the U.S. Nuclear Regulatory Commission, the U.S. Environmental Protection Agency, BNL, other national laboratories and private industry. In the early 1990's when BNL became actively involved in the DOE Office of Science and Technology research programs for subsurface barriers, it became increasingly apparent that the development of verification and monitoring technologies was lagging, while development of improved barrier materials and installation methods was being vigorously pursued. BNL recognized that it would be very difficult to obtain stakeholder acceptance of barrier technologies if the integrity and performance capabilities of the installed barrier could not be proven.

Subsequently, BNL proposed a uniquely capable, gaseous perfluorocarbon tracer (PFT) technology for subsurface barrier verification and performance monitoring. This technology uses a suite of gaseous perfluorocarbon compounds to detect holes, flaws, and breaches in a barrier and to measure performance characteristics of the barrier. Unlike geophysical methods, PFTs can be utilized under a very wide range of conditions including waste sites with large quantities of metals. Competitive gaseous tracer systems are less sensitive and rely on a single tracer. Having greater sensitivity and multiple tracers available allows the PFT technology a uniquely flexible system with unmatched accuracy and analytical proficiency. Recently, the PFT technology was extended to surface caps and cover systems.

This paper will briefly discuss the technical need for and the scientific basis of the PFT technology followed by a review of six successful field deployments of the technology. Four of the deployments centered on subsurface barriers, one was a proof-of-concept demonstration of cap/cover system verification, and the sixth was a leak test of a subsurface structure that closely mimics a subsurface barrier. The latter was used to characterize a subsurface cooling duct system and is included as it was a highly effective deployment that clearly illustrates the ability of the PFT technology and was well received by the principle responsible party (PRP), regulators, and stakeholders. The paper concludes with an outline of what needs to be completed to bring the PFT technology to a fully functional and fully commercialized verification tool that can be effectively deployed to facilitate site closure and long-term stewardship applications.

\subsection{Technology Need}

The PFT technology directly supports accelerated site closure needs outlined under Thrust I as recently defined by DOE EM-1. Fernald, Rocky Flats, and all of the smaller closure sites are planning to use some form of barrier to contain contaminants. In most cases these will consist of surface barriers, namely caps and cover systems (covers). To a lesser degree there may be implementation of subsurface barriers (i.e., slurry cutoff walls, 
containment barriers). With increased emphasis on near-term site closures (i.e., by 2006), cap and œver system verification and long-term monitoring have emerged as leading and urgent issues. In order to transfer control of these sites from DOE to state and local authorities, proven, working verification systems must be in place before site closure is completed. This technology may also support efforts under Thrust II to provide support for cost-effective solutions throughout the complex. For example, leak detection of underground piping and tanks can provide significant cost savings for characterizing contaminants in subsurface soils.

Some of these new covers are expected to maintain their performance for periods of up to 1000 years. In order for the cover to protect the environment it must remain free of holes and flaws throughout its service life. Covers are subject to subsidence, erosion, animal intrusion, plant root infiltration, etc., all of which will affect the overall performance of the cover. Long-term stewardship will require monitoring/verification of cover performance over the course of the designed lifetime. The need for a reliable method of verification and long-term monitoring is readily apparent. The BNL PFT technology can uniquely fulfill many aspects of verification and long-term monitoring.

Currently, containment system failures are detected by monitoring wells downstream of the waste site. Clearly this approach is inefficient, as the contaminants have already migrated from the disposal area before they are detected. Methods that indicate early cover failure (prior to contaminant release) or predict impending cover failure are needed. The BNL PFT technology can measure performance changes and integrity losses as the cover ages. This allows early detection of cover failure or pending failure so that repair or replacement can be made before contaminants leave the disposal cell.

The PFT technology fits best into SCFA Technical Targets \#5 and \#2 and to a lesser extent (or smaller payoff) may fit in Target \#6. Technical Target \#5 falls within the strategic investment category of Isolating Contaminants. The SCFA guidance states, "The targets in this category recognize that isolation and barrier technologies have been, and will continue to be, a primary tool in addressing environmental contamination. As a result, progress on these targets will positively impact both near term and future environmental management effectiveness in a realistic real-world scenario."

Technical Target \#5 addresses Advanced Sustainable Containment Systems. Containment systems cannot be considered sustainable if the long-term monitoring and stewardship concerns cannot be addressed. This is likely the biggest obstacle to closure many sites will have. There are many waste treatment technologies and cover system designs available for final disposition of waste streams, but very little available technology to address long-term stewardship issues. The Target states 'Properly applied and monitored, physical containment and barriers will remain a central activity in DOE environmental management for the foreseeable future. Advancing the science and technology base relatively rapidly is particularly important to closure sites that need to implement and document such systems in the next several years." 
The PFT technology can verify integrity, measure performance parameters (e.g., diffusivity), and monitor performance and integrity throughout the life of a cover. PFTs work with multi-layer systems and convoluted leak pathways, require simple equipment for analysis, and are extremely sensitive. The PFT technology, while not fully developed, has been proven in several deployments including a "hot" demonstration of subsurface barrier installation and a D\&D project at the BNL Brookhaven Graphite Research Reactor. For cover system/barrier verification and long-term monitoring, the PFT technology has much to offer once fully developed. The PFT technology can be fully developed in a relatively short time (i.e., to meet aggressive site-closure schedule needs) and promises a significant advancement over current technologies.

Technical Target \#2 addresses methods to verify and validate performance. To the extent that this target addresses containment as an approach for minimizing risks and/or costs associated with past contamination, then the PFT technology fits within this target. PFTs may also be useful in measuring contaminant flux (e.g., radon and VOCs) within a field. PFTs can be used as analogs to radon (for UMTRA covers) or VOC movement to determine if they are escaping the treatment zone. Developing the PFT technology for verification and long-term monitoring will also advance the use of PFTs for contaminant flux determinations.

Technical Target \#6 addresses Integrated Containment Treatment Concepts. The PFT technology can be used to monitor the performance of the containment system for the duration of the treatment. The gaseous tracers are non-reactive and non-scavenging so they are compatible with many treatment technologies. It will be harder to monitor containment with an ever-changing waste field. As the waste is treated and/or detoxified the signature of the field and containment may change. A monitoring system that is compatible with many different geotechnical variations, materials/chemicals and environmental conditions will prove valuable.

At the request of DOE, the ASME conducted a peer review of the PFT technology for cover system verification and long-term monitoring. Among their findings they stated; "Based upon the limited amount of field data collected at the DOE SRS Bentomat Cover Test Plot, it appears that the PFT technology will address the technical challenges of cover/capping system integrity verification. This project appears to be a logical extension of the previous PFT fieldwork on barrier integrity verification. The fiscal year 2001 field test results cited above adequately support the further development, testing, and modeling of this technology for cover/capping system integrity verification. These results give promise that PFT monitoring technology will address future DOE cover/capping integrity verification needs and long-term monitoring requirements."

\subsection{Background}

Recent decisions to accelerate clean up of the DOE complex and permanently close several sites with significant environmental problems, coupled with a greater recognition of the type and magnitude of problems faced, has forced a realization that both surface barriers (caps and cover systems) and subsurface barriers (walls and floors) are integral to 
a cleaner future. With this realization came an urgent need to develop verification and monitoring technologies that can address the stewardship requirements of barriers that may need to perform for 1000 years. A large number of surface barriers and to a lesser extent, but for more difficult situations, subsurface barriers will be needed in the near future. All of these barriers will require some form of long-term stewardship monitoring and/or verification.

Barrier uses include isolation of buried waste, secondary confinement of underground storage tanks, direction or containment of contaminant plumes, and restriction of other remediation methods (i.e., vacuum extraction or pump and treat) to a limited area. Effectiveness of a barrier depends on the continuity and number and size of flaws and breaches. A flaw or breach may be formed by discontinuous grout application, joints between panels that do not seal properly, or from cracking due to grout curing or wet-dry cycling.

As early as 1994 it was recognized that no suitable method existed for the verification of subsurface barrier integrity (In-Situ Remediation Program Needs Statement IS-9). The large size and deep placement of subsurface barriers makes detection of leaks challenging. This becomes magnified if the permissible leakage from the site is low. Detection of small cracks (fractions of an inch) at depths of 100 feet or more has not been possible using existing surface geophysical techniques. Compounding the problem of locating flaws in a barrier is the fact that no placement technology can guarantee the completeness or integrity of the emplaced barrier. The BNL PFT technology provides a system capable of filling the void for verification and monitoring of subsurface barriers and surface barriers, over a wide range of environmental and waste type/site conditions.

\subsection{PFT Monitoring/Verification Technology Description}

A tracer is any substance that can be easily or clearly monitored (traced) in the study media. Tracers for soil studies can be radioactive or non-radioactive liquids, gases, or solids. Tracer technologies can be used in transport/dispersion studies, leak detection studies, and defining material location. Leak detection studies use tracers to locate and estimate leak rates under various conditions. These can be as simple as colored dyes used to visually locate cracks and holes in tanks or as complex as mass spectroscopy detection of helium to find leaks in vacuum systems.

BNL has developed rapid and sensitive analytical methods for a host of perfluorocarbon tracers. These tracers were originally utilized in atmospheric and oceanographic studies and have since been applied to a great variety of problems including detecting leaks in buried natural gas pipelines and locating radon ingress pathways in residential basements. It was the prior accomplishments in determining radon gas pathways in residential basements that inspired the use of PFTs for barrier verification. The residential basements studied are essentially miniature "barriers" with vertical concrete walls and a horizontal concrete floor. Thus, it seemed clear that the PFT tracer technology should be directly applicable to finding leaks in barrier systems. 
Leaks (or areas of reduced performance) are located by injecting a series of tracers on one side of a barrier wall and then monitoring for those tracers on the other side (Figure 1). The injection and monitoring of the tracers is accomplished using conventional low-cost monitoring methods, such as existing vadose zone monitoring wells or multilevel monitoring ports, placed using penetrometer techniques (e.g. Geoprobe). The amount, type of tracer (speciation), and arrival times can all be used to characterize the size and location of a breach. It is easy to see that the larger the opening in a barrier the greater the amount of tracer that is transported across the barrier. Locating the breach requires more sophistication in the tracer methodology. Multiple tracer types can be injected at different points along the barrier, in both vertical and horizontal directions. Investigation of the spectra of tracers coming through a breach gives information on the location relative to the various tracer injection points. Arrival times of the different tracers can also be measured to obtain a more detailed analysis. Having multiple tracers also allows for confirmation of holes and differentiation between holes and spill over.

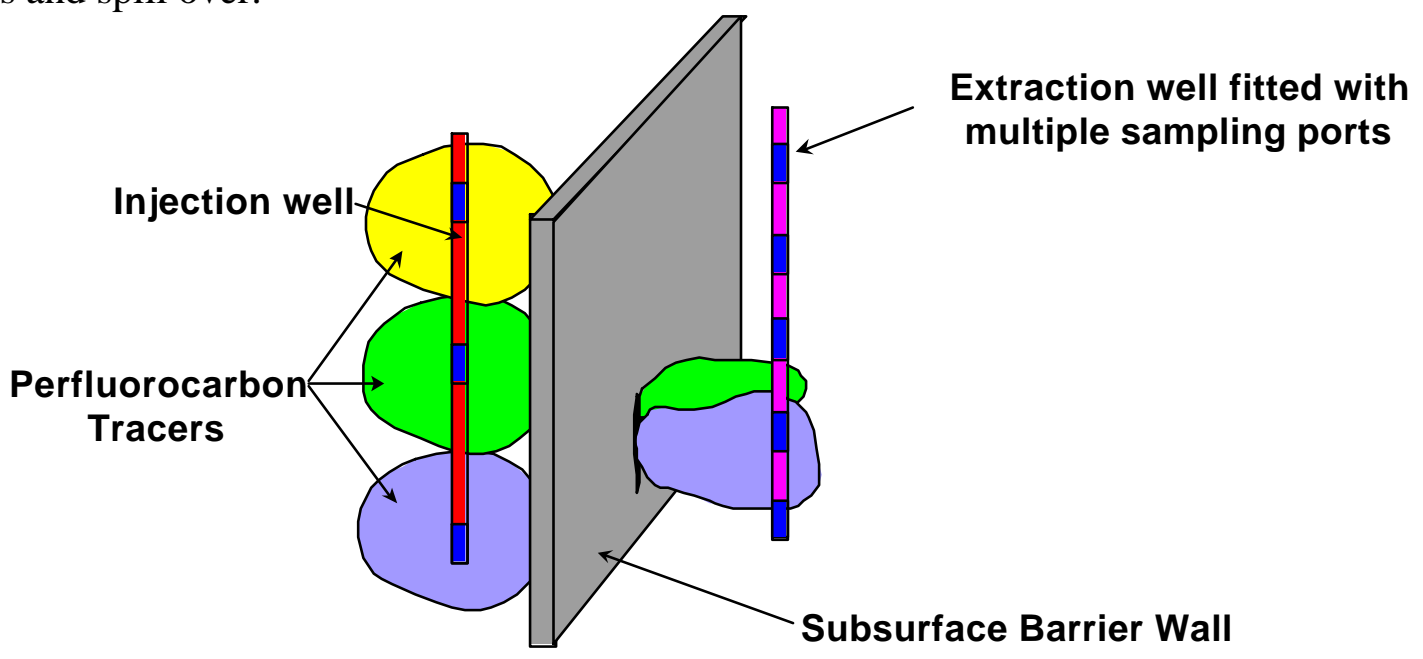

Figure 1 Schematic of PFT Technology with Multiple Tracers

PFT technology consists of the tracers themselves, injection techniques, samplers, and analyzers. PFTs have the following advantages over conventional tracers:

- There are negligible (a few parts per quadrillion) background concentrations of PFTs in the environment. Consequently, only small quantities are needed;

- PFTs are nontoxic, nonreactive, nonflammable, environmentally safe (contains no chlorine), and commercially available;

- PFT technology is the most sensitive of all non-radioactive tracer technologies and concentrations in the range of parts per quadrillion $\left(1\right.$ in $\left.10^{15}\right)$ are routinely measured. This allows detection of very small breaches in the barrier and/or using very small quantities of tracer;

- The PFTs technology is a multitracer technology permitting up to six PFTs (see Table 1) to be simultaneously deployed, sampled, and analyzed with the same instrumentation. This results in a lower cost and flexibility in experimental design and data interpretation. All six PFTs can be analyzed in fifteen minutes on a laboratory based gas chromatograph; 
- Several real time, portable instruments are available that allow rapid ( $<5$ minute) analysis of tracers (with slightly reduced sensitivity, part per trillion);

- PFTs can also be collected on adsorbent samplers specific for the PFTs. These samplers the elimination of field instrumentation if desired, as the samplers can be shipped to an off-site laboratory for PFT analysis.

Understanding mass transport through defects in barriers is central to the evaluation of barrier continuity. The migration of tracers was analyzed using computer codes that predict the transport of the gas tracer through a porous soil and barrier with defects. Existing computer codes can be adapted as necessary for the problem.

The PFT technology allows locating and sizing of breaches at depth and has been shown to have a resolution of fractions of an inch. The technology has regulatory acceptance and is used commercially for non-waste management practices (e.g. detecting leaks in underground power cables). This technology has been used in a variety of soils and will be applicable to the entire DOE complex as well as commercial waste sites. Tracers can be used to verify placement continuity of a freshly emplaced barrier and to re-check corrective actions that may be used to seal or repair a breach. The technology may however, prove to be most valuable as a tool for long-term monitoring of integrity and performance of barriers. Tracers would allow determination of performance losses in containment/isolation over the life of the barrier.

Table 1 Chemical Acronym, Name, and Formula for PFT Tracers

\begin{tabular}{|l|l|l|}
\hline Chemical Acronym & Chemical Name & Chemical Formula \\
\hline PDCB $^{1}$ & Perfluorodimethylcyclobutane & $\mathrm{C}_{6} \mathrm{~F}_{12}$ \\
\hline PMCP $^{1}$ & Perfluoromethylcyclopentane & $\mathrm{C}_{6} \mathrm{~F}_{12}$ \\
\hline PMCH & Perfluoromethylcyclohexane & $\mathrm{C}_{7} \mathrm{~F}_{14}$ \\
\hline pt-PDCH & Perfluorotrans 1,4 dimethylcyclohexane & $\mathrm{C}_{8} \mathrm{~F}_{16}$ \\
\hline oc-PDCH & ortho-cis-perfluorodimethylcyclohexane & $\mathrm{C}_{8} \mathrm{~F}_{16}$ \\
\hline PTCH & Perfluorotrimethylcyclohexane & $\mathrm{C}_{9} \mathrm{~F}_{18}$ \\
\hline
\end{tabular}

Chemically distinct isomers

\subsection{Advancing the PFT Technology to Meet the Needs of Closure Sites}

The PFT technology is expected to and has been shown to operate under a variety of conditions. The technology is unaffected by waste type, temperature (within the confines of expected environmental temperatures at waste sites), or $\mathrm{pH} / \mathrm{eH}$. Tracer transport is affected by geologic or physical differences such as soil type, layering degree of fracturing, or void volume, but all of these are expected variations and are easily accounted for (through normalization, modeling, or experimental measurement). The fundamental principals behind the technology's operation and hence success remain unchanged.

Two parameters that can adversely effect PFT measurements are soil moisture and barometric pressure. As soil moisture content increases, the air-filled porosity of the soil decreases and therefore changes the transport rate of the tracers. For subsurface barriers this has not been an issue. For the range of soil moisture encountered in deeper soils 
(>10 feet) no significant changes occur in soil moisture over the duration of a test and therefore, transport rates are unaffected and this parameter can be ignored. For surface barriers, soil moisture issues are a greater concern. Cover systems can be at saturated conditions in the upper layers after a severe rainfall event. This would "clog" the pore structure and drastically reduce tracer transport. For lesser degrees of saturation, the effect would be a reduction in transport. The relationship of tracer transport rates versus soil moisture content needs to be determined. Once the relationship is known it can be accounted for or minimized (e.g., by not testing immediately after a severe precipitation event).

Barometric pressure is only important to cover system measurements and only through barometric pumping. Rapid changes in atmospheric pressure can cause pumping of the soil gases to the surface. This phenomenon is limited (in terms of affecting PFTs) to the first 3 to 5 feet of soil and thereby does not effect subsurface barrier measurements. Experience at the SRS site showed that even with a very shallow surface layer ( $\sim$ foot) barometric pumping would not preclude the technology from successfully verifying the cover. The dilution of the tracer due to near-surface effects was about one order of magnitude and is well within the range of the technology's sensitivity. The tracer technology could afford an additional two to three orders of magnitude dilution before the effect would require changes to the normal operating conditions. PFT concentrations can also be increased from the normal $1 \mathrm{ppm}$ target to $1000 \mathrm{ppm}$, giving an additional three orders of magnitude sensitivity. The PFT technology is capable of handling five orders of magnitude greater dilution than barometric pumping has been observed to cause.

The limitations of the PFT technology can be easily accommodated by performing laboratory and field experiments to determine the relationship of soil saturation to tracer transport rates. Some additional modeling efforts would be required to incorporate barometric parameters into the overall technology application. In addition, more data is needed on the transport of tracers through various materials and soil types. Laboratory experiments would be valuable in broadening the applicability of the PFT technology.

In the ASME peer review of the PFT technology it was stated; "The basic science approach to gas tracer cover/capping system integrity validation is sufficiently understood to guide further development activities. Adequate location and characterization of cover/capping defect areas are essential for risk evaluation. Therefore, further understanding of the contaminant transport through different soil and material types and its effects on gas tracer technology is needed."

The review panel further stated, "This project addresses the DOE-identified needs for Verification, Monitoring, and Stewardship of cover/capping integrity. With further development, modeling, and testing, the likelihood of deploying PFT technology at DOE sites is reasonably high." The peer reviewers concluded, "This technology potentially provides a mechanism for cost-avoidance and cost-savings at both existing and new cover/capping systems." 
For cover system assessment, the following issues require additional development so that the PFT technology can be considered fully functional, fully developed (all capabilities utilized), and commercially viable.

- The development of the PFT technology for cover/capping integrity verification lacks adequate theoretical modeling. The modeling capabilities need to be improved and a "user friendly" final software package should be developed. The ASME panel suggested, "The Project Team should plan, design, and execute additional PFT cover/capping integrity verification testing under controlled conditions using well-developed sampling protocols. The Project Team should design its field tests using theoretical modeling. The Project Team should finetune its models through calibration with results from multiple DOE-site field tests."

- For deployment at existing cover/capping systems, further development and fieldtesting of surface and/or above ground sampling protocols for the effective use of this technology.

- Consistent protocols for the installation of the PFT technology as part of existing and new cover/capping systems need to be developed.

- A cost estimate and life-cycle assessment need to be developed. The technology developers have spoken with several commercial interests including an instrument manufacturer (to produce and sell or rent PFT instrumentation), technology vendor to provide complete packages, and service vendors to provide PFT technology to sites as a service contract. While initial interest is high and the instrument vendor is ready to provide units, no formal cost estimate has been performed, as the technology is not yet fully developed. The cost analysis and commercialization needs to develop in parallel to the technology.

\subsection{PFT Technology Deployments}

The PFT technology for verification and monitoring began as a subtask to the full-scale demonstration of a close-coupled subsurface containment barrier at Hanford in 1995. This test was designed solely as a proof-of-concept test. This test was followed by two other basic (close-coupled and viscous liquid barriers at BNL) deployments that showcased the PFT strictly as a leak test system and did little to further the development of the technology in terms of resolution, modeling, or predictive capabilities. The fourth deployment of PFTs was completed in 1997 at an engineered test facility and was designed to investigate the resolution of the PFT technology and to compare it to a single tracer system $\left(\mathrm{SF}_{6}\right)$. In 2000 , the PFT technology was applied to a slightly different problem. The system was used to define the leak pathways from two, large, subsurface air ducts that had been formerly used for air-cooling of a research reactor. The results of the leak test were used to guide soil characterization studies. The last deployment was a proof-of-principle test of the PFT technology for a surface cover at the Savannah River Site Bentomat Cover Test Facility. This section will briefly describe each deployment, the successes of each and the lessons learned. 


\subsection{The Hanford Close-Coupled Barrier}

\section{Key Successes}

- First deployment of PFT technology and successfully demonstrated, on a proofof-concept level, that the technology was capable of verifying barrier integrity.

- Was able to measure barrier performance by estimating (order of magnitude) the diffusion coefficient of the cement layer of the barrier.

The first deployment of the PFT technology was at Hanford as a small subtask to a subsurface barrier demonstration. The primary objective of the demonstration was to develop and demonstrate in-situ emplacement of a close-coupled barrier technology. A secondary objective of this project was to provide a demonstration barrier for integrity verification technologies, including the PFT technology. This deployment successfully demonstrated, on a proof-of-concept level, that the technology was capable of verifying barrier integrity by determining that no breaches existed in the demonstration barrier. The technology was also used to measure barrier performance by estimating (order of magnitude) the diffusion coefficient of the cement layer of the barrier.

A close-coupled barrier is produced by first installing a conventional, low-cost, cementgrout containment barrier followed by a thin lining of a polymer grout. The two grouts are placed in a close-coupled fashion such that the polymer barrier is bonded to the cementitous barrier. The resultant barrier is a cement-polymer composite that has economic benefits derived from the cement and performance benefits from the durable and resistant polymer layer (see Figure 2).

The site selected for the field-scale demonstration was the Hanford Geotechnical Development and Test Facility in the 400 Area ("Little Egypt") at the Hanford Site near Richland, Washington. Details of the barrier construction can be found in the references. A monitoring network was installed prior to grouting and consisted of a series of wells (with perforated casings) spaced every 45 degrees located parallel to and approximately one meter outside the area to be grouted. 


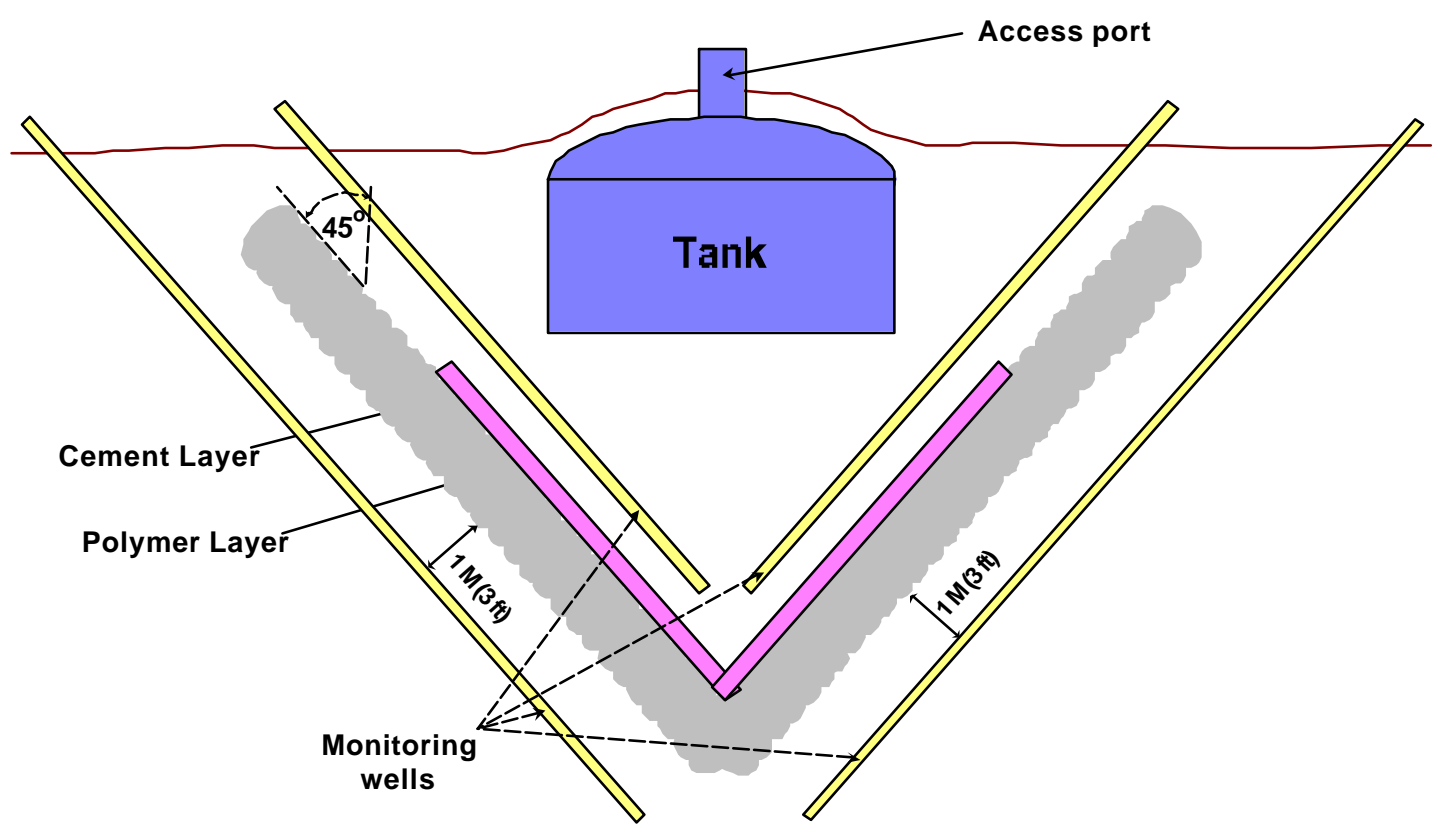

Figure 2 Schematic of the Close-Coupled Barrier at Hanford

The cement layer was installed first, using conventional jet-grouting methods and was allowed to cure for thirty days before verification using the PFT technology. PFT injection started on October 18, 1995 and lasted for three days at a nominal rate of 15 $\mathrm{cm}^{3} /$ min (measured rates varied between $12-15 \mathrm{~cm}^{3} / \mathrm{min}$ ) at a PMCH source concentration of $373 \mathrm{ppm}$. The target goal for the interior concentrations was $1 \mathrm{ppm}$. The monitoring wells were used to draw soil gas samples to measure the PFT concentration as a function of time (Figure 3). The results of the tracer testing indicated that the barrier was intact and breach free. Simulations of tracer movement were performed using the computer code BLT. A best fit was obtained using a soil diffusion coefficient of $2 \times 10^{-2} \mathrm{~cm}^{2} / \mathrm{s}$ and a cement barrier diffusion coefficient of $2 \times 10^{-3} \mathrm{~cm}^{2} / \mathrm{s}$.

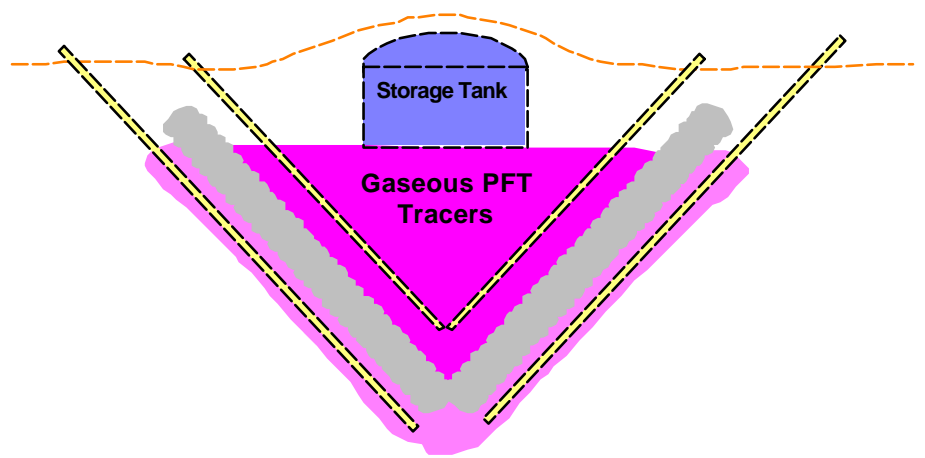

\section{Figure 3 Using PFTs to Verify the Cement Layer at the Hanford Barrier}

After completing the tests and analyzing the data (and determining that the cement layer was continuous and leak free), the polymer grout was injected in December of 1995. In March of 1996, another PFT, oc-PDCH, was injected into the interior of the barrier as before. The injection started on March 3 and lasted for three days at a nominal rate of 15 
$\mathrm{cm}^{3} / \mathrm{min}$ at an oc-PDCH concentration of $30 \mathrm{ppm}$. Again, the target interior concentration was $1 \mathrm{ppm}$. Analysis of the data showed the polymer layer to be leak free.

The fact that the barrier emplacement was successful in that no large breaches were formed prevented field-scale demonstration of the accuracy of PFTs in defining a breach. Model evaluations indicated the feasibility of locating breaches down to a few $\mathrm{cm}$ in size. However, experimental verification of this concept was needed. It was recommended that future testing be performed on subsurface barriers with pre-formed breaches of known location, size, and geometry.

This deployment was very successful as a simple proof-of-concept demonstration and was designed with a very limited budget to provide evidence that this technology was feasible and deserving of further development. After the data analysis was carried as far as possible it was evident that more experience was needed in the application and development of simulation models used to estimate the size and location of potential small-scale breaches or barrier imperfections for realistic geometries and on the field scale. Areas with unresolved issues included: transport parameter estimation, breach location and size determination, the role of advection on transport, estimation of spacing requirements between PFT monitoring locations that are needed to define a breach, inverse modeling to define a breach, the role of small-scale heterogeneities and experimental uncertainties in influencing estimates of breach location, and the role of simultaneous use of different PFT tracers to evaluate barrier performance.

\subsection{Brookhaven National Laboratory Chemical Waste Pits}

\section{Key Successes}

- Acceptance of the PFT technology by regulators as a suitable verification tool.

- First application of PFT technology at an actual remediation site.

Following the successful demonstration at Hanford, full-scale implementation of closecoupled barrier technology was performed at BNL's Glass Hole Waste Site. During the 1960's through the early 1980's, an area designated as the AOC 2C glass bottle pits was used for the disposal of laboratory wastes (contaminated glassware and laboratory chemicals). In response to detection of contaminants in the soil and groundwater below these pits, site evaluations and development/demonstration tasks were conducted to determine safe and cost-effective remediation technologies for closure of AOC $2 \mathrm{C}$. The scope of this project was to emplace a low-permeability, interim containment barrier beneath Glass Bottle Pit G-11 without disturbing the waste pit or its contents. This installation was performed following the same engineering principles as the Hanford barrier with the following alterations: the site is an actual remediation site, a V-trough shape was chosen to eliminate the excessive grout usage at the apex of the cone-shaped barrier, the barrier was designed for interim (3-5 years) containment.

In addition, a demonstration of in-situ stabilization of the waste buried in the pit was performed. The PFT technology was again deployed in a leak-detection mode, but this 
time to provide assurances to the local regulators that the barrier formed would contain the stabilization efforts and prevent contaminants (pure liquid solvents existed in laboratory containers in the pits and would be ruptured during jet-grouting stabilization) from entering the groundwater, which was in close proximity to the bottom of the pit. Without the PFT technology it is doubtful the in-situ stabilization task would have proceeded.

The containment utilized the close-coupled barrier concept and was composed of a Vtrough shaped cement grout "bath tub" that served as a backdrop for a thin liner of a polymer grout (Figure 4$)$. The thin $(0.3$ meters) polymer layer, being very low permeability and chemically resistant, composed the primary barrier to contaminant mobility. The cementitous layer was thick ( 1 meter) and served as a secondary barrier to contaminant mobility. The composite barrier was engineered to act as an interim safety net, catching any liquid that might escape from the pit during solidification or other remediation activities.

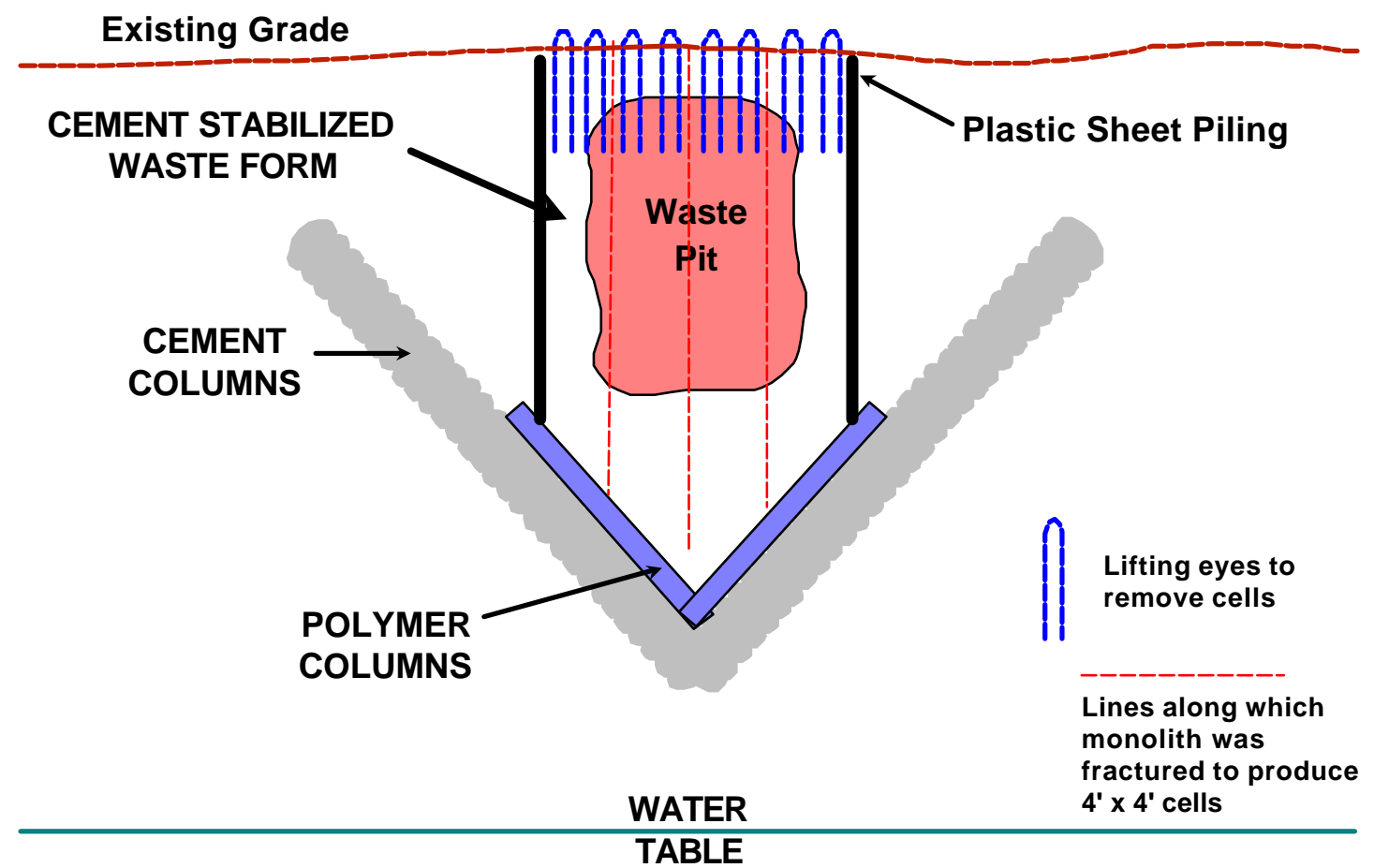

Figure 4 Schematic of Barrier Installation at the BNL Chemical Waste Pit G-11

After installation, the barrier was checked for leaks using the PFT technology. In this test, the objective was to demonstrate that a large-scale breach in the barrier did not exist. This was needed in order to satisfy regulator concerns that liquid wastes would be released during waste stabilization or removal operations. The PFT oc-PDCH was injected inside of the cement grout barrier at $30 \mathrm{ppm}$ and a nominal flow rate of 15 $\mathrm{cm}^{3} /$ min. The injection and monitoring of the PFTs was accomplished through vadose zone wells (Figure 2). The monitoring wells were installed parallel to the barrier walls. Placement was accomplished using a truck-mounted Geoprobe unit and frost augers. 
Upon determination that the barrier was continuous and breach free, the in-situ stabilization was allowed to proceed. [This portion of the project was experimental in nature and was designed to evaluate the effectiveness of in-situ stabilization.]

During the summer of 1997, final remediation of the Glass Pits area was accomplished by excavating the waste pits. At the same time pit G-11 was also excavated. During the excavation and removal of the monolith and barrier a limited visual inspection was performed. No large-scale breaches were observed further confirming the PFT verification results. In addition, no contaminated soil was found beneath the barrier.

Once again, the funding for the PFT task only allowed for a rudimentary leak test. No refinement to the PFT technology occurred other than additional experience and confidence in the implementability of the technology for verification and monitoring.

\subsection{Colloidal Silica (Viscous Liquid) Barrier}

\section{Key Successes}

- The PFT technology was the most successful verification tool used at the demonstration. Geophysical methods did not come close to accurately defining holes and the single tracer system from SEA, Inc. could not differentiate between spill over and leakage near the top of the barrier. Excavation of the barrier proved the PFT technology to have accurately defined the leaks and flaws in the barrier.

- Data was very stable and provided a consistent picture throughout the one-month sampling period.

During the summer of 1997 a subsurface barrier was installed at BNL. The barrier consisted of a colloidal silica (CS) grout that was placed using permeation grouting. Upon gelling, the grout forms an impermeable barrier that can be used to contain subsurface contaminants. The barrier was installed at a clean site near the Glass Pits Disposal area in OU I. BNL was chosen as the cold demonstration site due to the geology (porous sand matrix) and the stated possible need for containment barriers in future remediation efforts.

CS was injected into the subsurface in an attempt to provide an impermeable barrier for waste isolation. The internal dimensions of the barrier form approximately a twenty-foot square with the barrier walls nominally 4.25 feet thick. The west wall of the barrier was injected at a 45-degree angle to the ground surface and the east wall installed vertical. This resulted in the north and south walls (installed vertically) having a triangular shape.

Upon completion of the CS barrier, testing of the barrier's integrity using the PFT technology, sulfur hexafluoride $\left(\mathrm{SF}_{6}\right)$ gas tracer, and geophysics was initiated. Both tracer systems used the same monitoring ports. The injection and monitoring port system contained eighteen sampling locations (boreholes) with one to five sampling ports at each location. The total number of exterior monitoring ports was 54. In addition, there were five injection/monitoring wells located inside the region bounded by the CS barrier. 
This PFT technology deployment was again a rudimentary leak test but also allowed some analysis to refine information on flaw location. The primary objective was to test the barrier integrity by injecting PFTs inside the barrier and measuring their concentration outside the barrier as a function of time. Three tracers, (PMCH, PMCP, and oc-PDCH) were injected simultaneously at different points from September 10 - 15, 1997. Sampling of all 54 ports along the walls of the CS barrier was completed in one day and all walls were sampled at least once per week. Sampling began September 11 and ended October 23 with over 450 samples collected.

As in previous studies, the tracer flow was determined to be diffusion controlled. The data provided a consistent picture throughout the one-month sampling period and the PFT technology was successful in identifying two locations with weak barrier integrity.

The east vertical wall showed leakage centered at a depth of fifteen feet below grade approximately twelve feet into the panel. In addition, leakage over the top was demonstrated at the far right (panel distance greater than 30 feet) (Figure 5). The first leak was detected by the tracer oc-PDCH and the surface leak was detected with the $\mathrm{PMCH}$ tracer. This reflects the relative distance between the injection point and these sampling locations for each tracer. Samples taken at later times provided similar results. All of the data showed elevated concentration levels in the same region of the barrier and leakage over the top.

The west (slant) wall also shows evidence of leakage (Figure 6). The leak in the bulk of the wall is nearly twelve feet into the panel at a depth of seventeen feet below grade. This leak was first detected with the tracer PMCH. Leakage also occurred over the top of the panel as shown from the oc-PDCH contours in Figure 6. Contours obtained at later times showed approximately the same distribution of tracer. This leak was easily confirmed upon excavation of the barrier. The leak developed from a misaligned column. When the injection rod was pushed into the subsurface it "wandered" off course. The result was similar to a plank floor with one plank pried upward. Gas (and of course contaminants) could leak out at the point that the column was lifted high enough to create an opening. Figure 7 presents two photographs of the excavated CS barrier, shown from the north and south views. In the left hand photograph the misaligned column is clearly visible, jutting up about 6 feet from the sidewall. This was a major find for the PFT technology, as the geophysical methods did not see this as a flaw. 


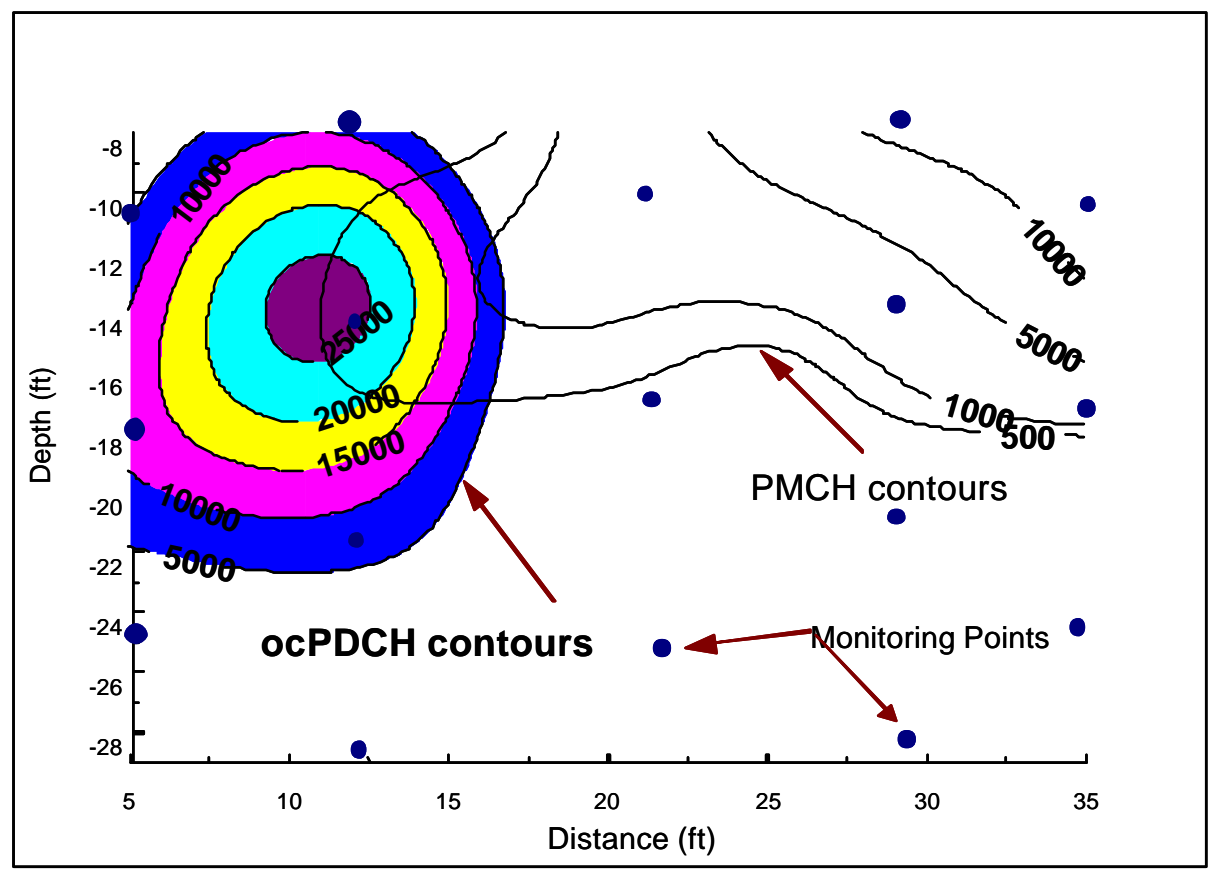

Figure 5 Color Contours for the Tracer oc-PDCH at the East Wall

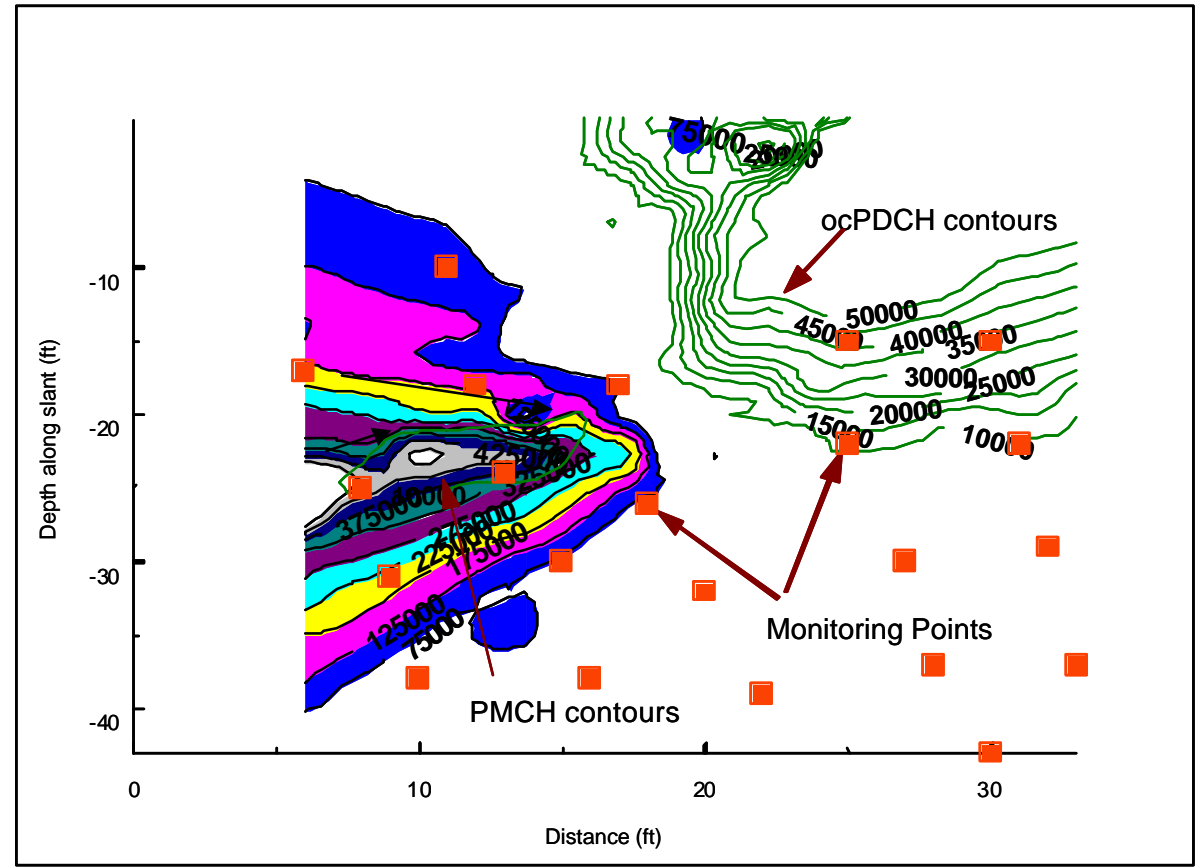

Figure 6 Color Contours for the Tracer PMCH at the Slant Wall 

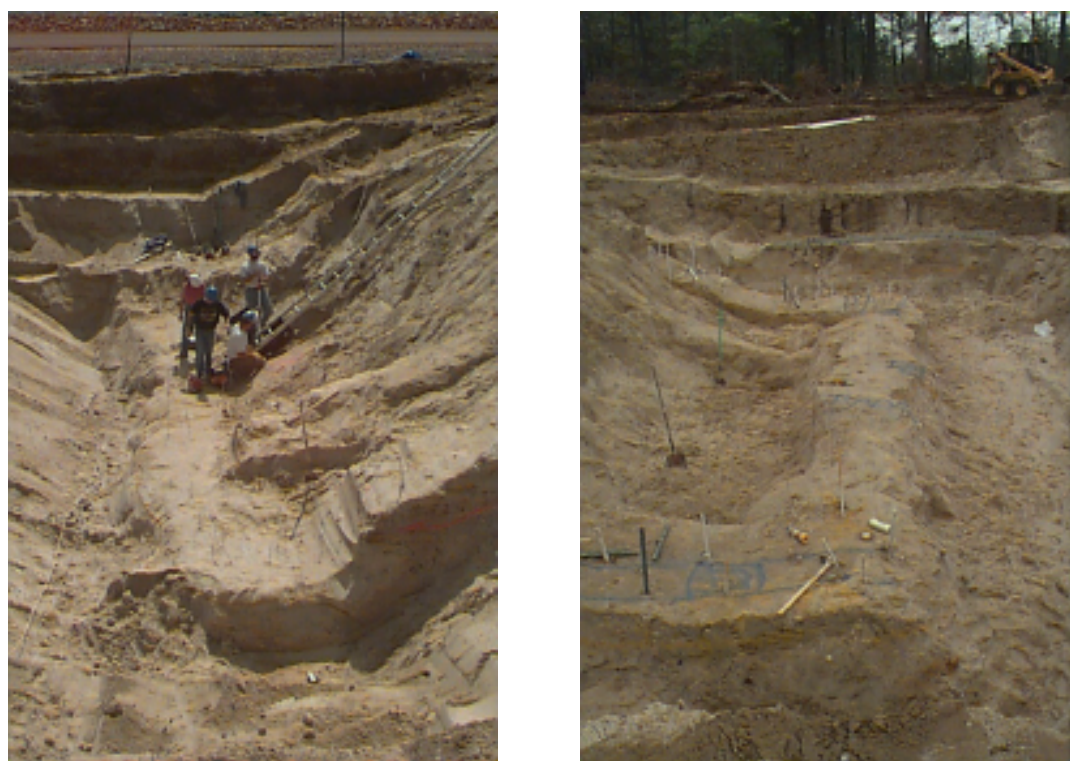

Figure 7 Excavation of the CS BarrierShowing a Major Flaw in the Slant Wall

\subsection{Waldo Test Site}

\section{Key Successes}

- The PFT technology was used to detect a total of seven flaws. This included the six engineered flaws and one non-engineered flaw at a seam between the north and east walls. Multiple flaws were detected on the east (three flaws) and north (two flaws) walls.

- The use of multiple tracers allowed monitoring of transport around the barrier. This permitted differentiation between tracers originating from spillover, flaws on the other sides of the barrier (and moving underneath or around the barrier), and flaws in seams of the barrier. This capability is lost with single tracer systems and the $\mathrm{SF}_{6}$ tracer system failed to detect the seam leakage as it could not differentiate seam leakage from overflow of tracer from the top (or from holes in the sides).

- The use of multiple tracers provided simultaneous and independent confirmation of flaw locations.

- The PFT data were used to accurately determine the relative size of the flaws in each barrier.

BNL tested the PFT technology on a subsurface barrier with known, engineered flaws at the Waldo test facility [operated by Science and Engineering Associates, Inc (SEA)]. The tests involved the use of five unique PFT tracers with a different tracer injected along the interior of each of the four walls of the barrier. A fifth tracer was injected exterior to the barrier to examine the validity of diffusion-controlled transport of the PFTs. The test was also used to compare the PFT technology to a single tracer system developed at SEA. 
The SEA system utilizes $\mathrm{SF}_{6}$ as the tracer and has less sensitivity than the PFT technology due to greater natural background levels of the tracer.

The objective of this set of tests was to be able to determine the accuracy with which PFTs could locate and determine the size of known flaws in a subsurface barrier. SEA installed a test facility for this purpose; a complete description of the facility and test plan for this project can be found in the references. The test volume consisted of a small-scale barrier with monitoring points both internal and external to the barrier. The shape and the dimensions of the barrier were chosen to be realistic, easily constructed, and capable of allowing a multitude of leak combinations to be tested (Figure 8). A V-shaped trench roughly 5-meters deep and 15-meters long was excavated. The sidewalls and ends of the trench were sloped roughly $45^{\circ}$ from horizontal.

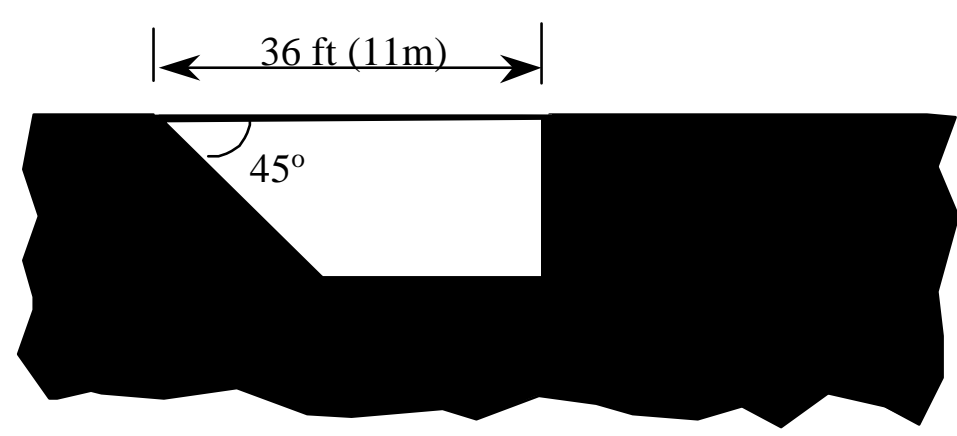

SIDE VIEW

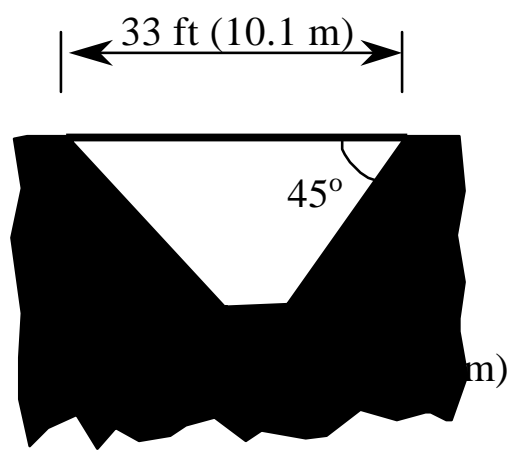

END VIEW

\section{Figure 8 Sche matic of the Waldo Test Barrier}

After excavation, the south, east, and west walls of the trench were lined with a 4 inch layer of shotcrete, then a 30-mil thick sheet of plastic to create an impermeable barrier. The north wall, designated as the Framed Wall in Figure 8, was covered with plastic. The region outside of the Framed Wall in Figure 8 was backfilled and is more permeable than the native soils. Once the barrier was completed, the trench was also backfilled.

A series of 23 monitoring wells were placed exterior to the barrier. The wells were spaced approximately six feet apart at the surface. Within each well, there were one to four monitoring ports at different depths. The distance between ports within a well was also approximately six feet. In total, there were 62 external ports. The depths of the monitoring ports were staggered between wells to provide more efficient coverage of the subsurface region. The test barrier had six known flaws open during the test.

The test began with the injection of five different PFTs: $\mathrm{PMCH}$, oc-PDCH, p-PDCH, $\mathrm{PTCH}$, and PMCP. Four of the tracers were injected in the center region of the barrier near the centroid of each wall approximately one to two feet below grade. The fifth tracer, PTCH, was injected outside of the barrier in the fractured shale layer at a monitoring port on the west wall. This tracer was used in an attempt to gain a better understanding of flow through this layer and the clay and alluvial layers above. The tracer concentrations in the injected air ranged from a few ppm to approximately one 
thousand ppm. The PFTs were injected for 3 days at a nominal flow rate of $15 \mathrm{~cm}^{3} / \mathrm{min}$. Samples were taken from all monitoring ports on a daily basis.

The data were analyzed using a gas chromatograph to determine the concentrations of the tracers in each sample. These data were organized by the location of each sample point and a two-dimensional contour plot was generated for each day, wall, and tracer type using Surfer ${ }^{\mathrm{TM}}$. Over 100 contour plots were produced to examine the outcome of the test. Figures 9 and 10 are representative of the findings.

Figure 9 shows the time evolution of PMCH detected in the monitoring ports on the west wall. PMCH was the tracer injected closest to the west wall and appears on the first day of sampling outside of the barrier. The concentrations show a remarkably consistent pattern for the duration of the experiment with the normalized concentration increasing from $10^{-5}$ to almost $10^{-4}$ after 5 days. There is a slow decrease in concentration for the remainder of the experiment. The data support a single flaw in the barrier located at $8.8 \mathrm{~m}$ (Northing) and $-2.65 \mathrm{~m}$ depth.

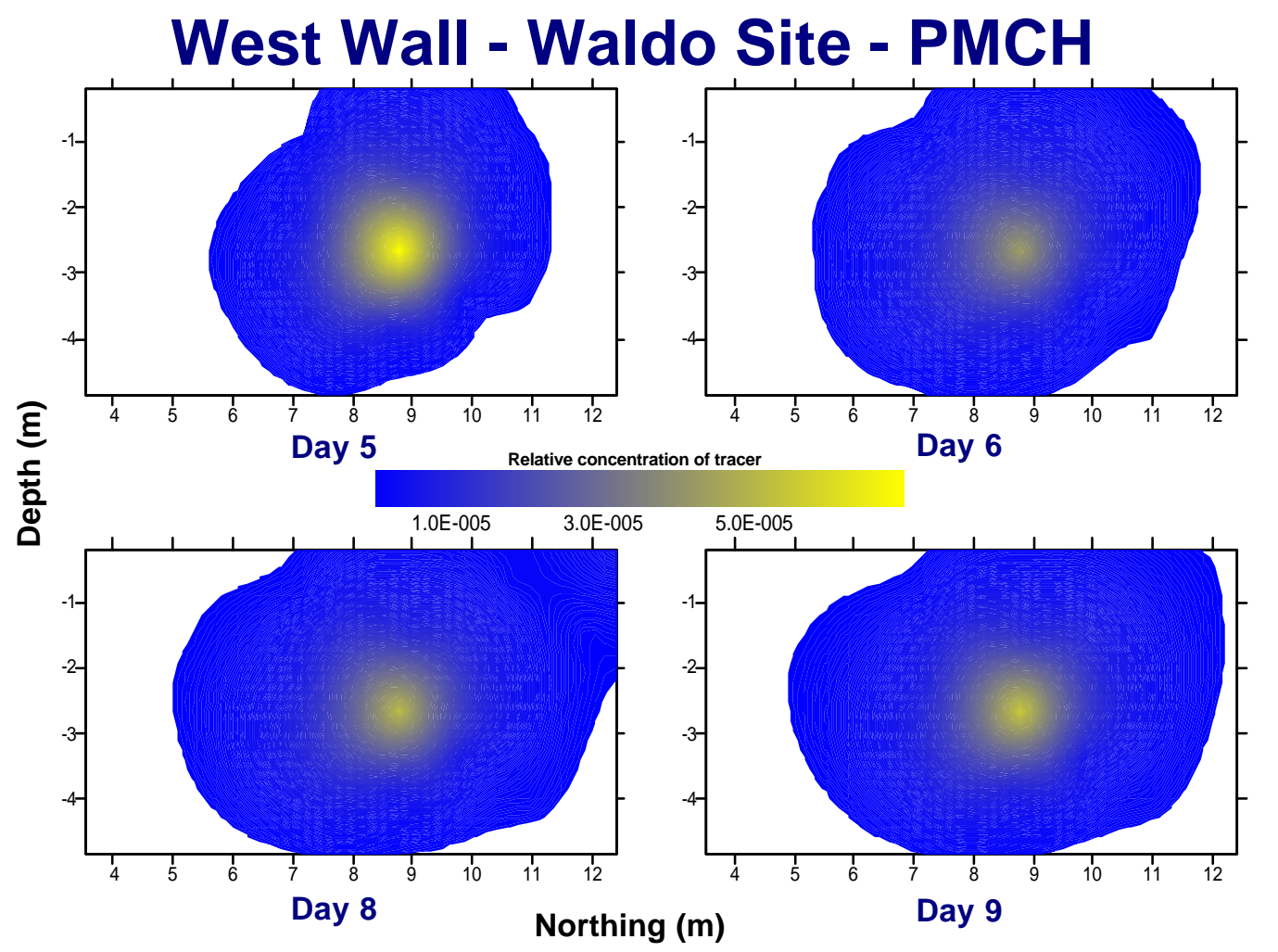

Figure 9 PMCH Contours for the West Wall at the Waldo Test Facility - Days 5 to 9

Figure 10 shows the time evolution of PDCB detected in the monitoring ports on the west wall. PDCB was injected in the interior near the south wall approximately five meters from the injection location of the PMCH. During the first few days of sampling, PDCB was detected at normalized concentrations of less than $3 \times 10^{-7}$ at the lower left corner region of the diagram. This is near the intersection of the south and west walls. The PDCB normalized concentration was two orders of magnitude lower than the levels of PDCB on this wall. At Day 9, PDCB was detected in the region of the flaw detected by 
$\mathrm{PMCH}$. The normalized concentration in this region increased to a maximum of $2 \times 10^{-6}$, and was the highest measured PDCB concentration on this wall. This PDCB data independently confirms the flaw at $8.8 \mathrm{~m}$ Northing and $-2.65 \mathrm{~m}$ in depth. The concentrations at the lower left corner could be from a leak at the seam or from spill over from the hole on the south wall of the barrier. The concentration data for PDCB from the south wall indicate that this is due to movement around the outside of the barrier originating from the flaw in the south wall. This is further supported by the absence of any indication of a leak at the seam from the PMCH data. The use of distinct tracers was essential in determining if the concentration in this region was due to a flaw at the seam or due to transport around the outside of the barrier of tracer originating from another flaw.

Data from other walls showed similar results. The south wall also had one flaw that was easily detected with the PFTs. The north wall had two small holes that were located by the PFTs. The east wall had three flaws. Two of these were engineered flaws, and the third occurred at the seam between the north and east walls. The non-engineered leak was confirmed by the pt-PDCH injected on the north wall and the PMCP injected on the east wall.

The tracers were able to accurately detect the presence of the engineered flaws. Two flaws were detected on the north and east walls and one flaw was detected on the south and west walls. In addition, one non-engineered flaw at the seam between the north and east walls was also detected. The use of multiple tracers provided independent confirmation of the flaws and permitted a distinction between tracers arriving at a monitoring port after being released from a nearby flaw and non-engineered flaws. The PFTs detected the smallest flaw, 0.5 inches in diameter. Visual inspection of the data showed excellent agreement with the known flaw locations and the relative size of the flaws was accurately estimated.

Comparison of the projected flaw locations and the actual locations of the flaws showed excellent agreement. The location of the six flaws was projected within one or two feet of the actual location. This estimate could have been enhanced by numerical modeling of the movement of the PFTs in the subsurface. One non-engineered flaw was detected at the seam between the north and east walls. 

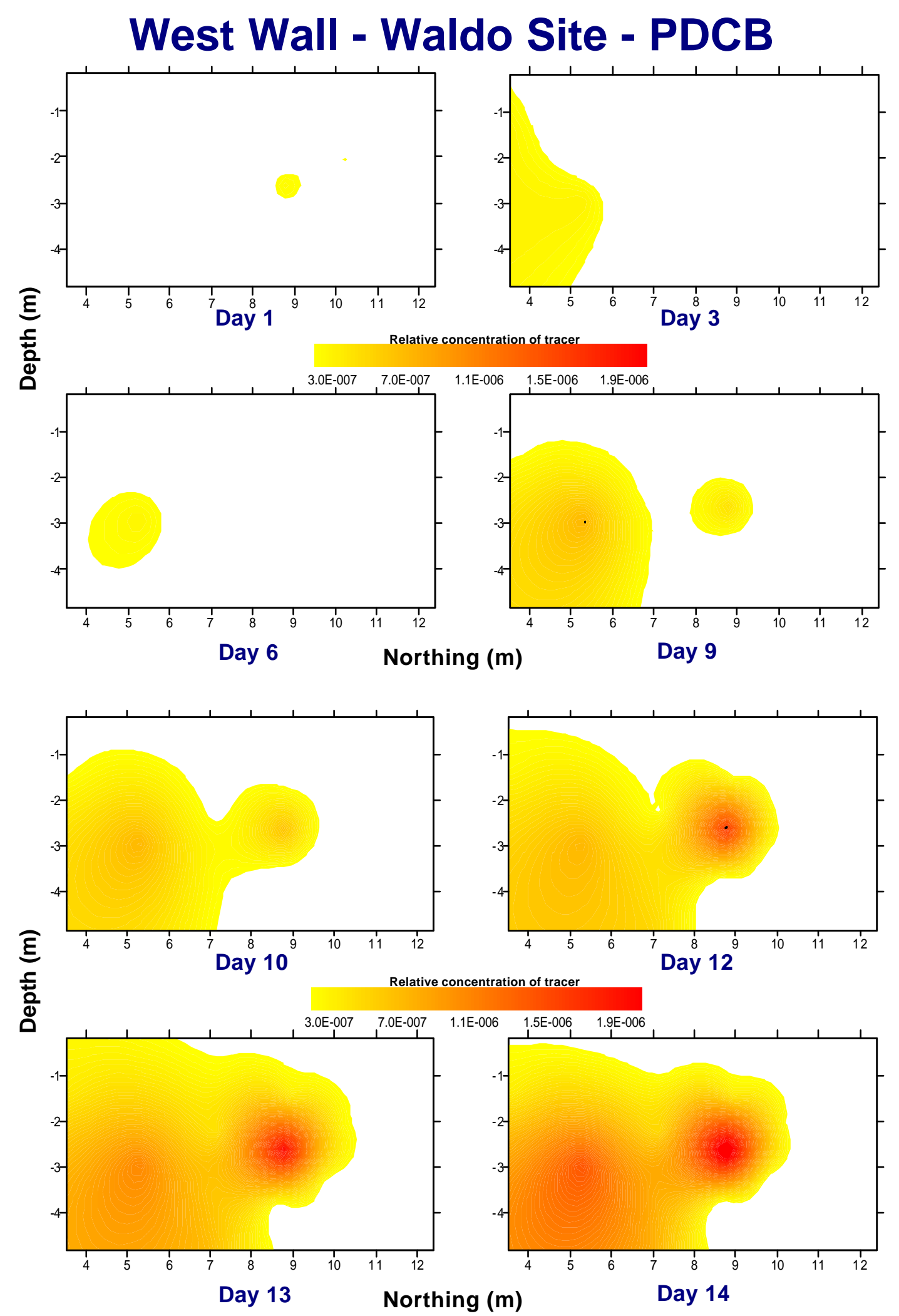

Figure 10 PDCB contours for the West Wall at the Waldo Test Facility - Days 1 to 14 
Without detailed numerical modeling, it was not possible to estimate the flaw size. However, it is possible to examine the relative size of the flaws directly from the data. The data show reasonable agreement with the actual flaw sizes. Normalizing the largest radius to 1 (East wall), the relative radius for the largest hole on each wall is 0.27 for the south and west walls, and 0.067 for the North wall. The data measured the relative flaw size within $25 \%$ of the actual relative flaw sizes.

The PTCH tracer that was injected on the outside of the barrier demonstrated diffusioncontrolled behavior on the exterior. It was only detected on the interior at one location during one sample collection period. This indicates that the area for flow into the barrier is small compared to the area for flow outside of the barrier. This is consistent with the small flaw sizes as compared to the total area.

The major findings of the experiment are:

- The PFTs were used to detect a total of seven flaws. This included the six engineered flaws and one non-engineered flaw at a seam between the north and east walls. Multiple flaws were detected on the east (three flaws) and north (two flaws) walls.

- The use of multiple tracers provided simultaneous and independent confirmation of flaw locations.

- The use of multiple tracers allowed monitoring of transport around the barrier. This permitted differentiation between tracers originating from flaws on the other sides of the barrier moving underneath the barrier and flaws in seams of the barrier. This capability is lost with single tracer systems [The $\mathrm{SF}_{6}$ tracer system failed to detect the seam leakage as it could not differentiate seam leakage from overflow of tracer from the top].

- The PFT data were used to accurately determine the relative size of the flaws in each barrier. The east wall clearly had the largest flaw, the south and west walls had similar size flaws, and the north wall had the smallest flaws.

Numerical modeling of the hole sizes and locations was beyond the scope of work for this project. However, it is needed to improve definition of flaw size and location.

\subsection{Brookhaven Graphite Research Reactor (BGRR)}

\section{Key Successes}

- The PFT technology allowed the determination of the leak paths and relative size of the leaks in the Below Grade Ducts (BGD) without having to unearth and inspect the ducts. The information gained was used to guide the soil characterization.

- The PFT technology allowed rapid determination of the leaks from the BGD.

- Multiple tracers allowed for confirmatory data for all leaks. 
- The technology was accepted by regulators as a leak detection tool and was well received by stakeholders.

The BGRR was the world's first nuclear reactor dedicated to the peaceful exploration of atomic energy. The reactor pile consisted of a 700-ton, 25-foot cube of graphite fueled by uranium. Cooling air, flowed through and around the reactor core, then through an exhaust duct containing filters, and finally out through the 320-foot high exhaust stack.

The BGRR ceased operation in 1968 and was placed in a shutdown mode. The final decommissioning process was initiated in 1999, and is scheduled for completion in 2005. An accelerated schedule was developed that combines characterization with removal actions for the various systems and structures. One of these structures is the BGD that connected the exhaust plenums with the fan house. The air plenums experienced water intrusion during BGRR operations and after shutdown. The water intrusions were attributed to rainwater leaks into degraded parts of the system and to internal cooling water system leaks.

Figure 11 depicts the layout of the BGRR duct facilities. The BGD is approximately 170 feet long, running from the Reactor building to the above ground joint. Each of the north and south exhaust air-plenums are approximately ten feet wide and fourteen feet high and are highly contaminated. The ducts are constructed of one-foot thick reinforced concrete, lined with two layers of carbon steel. The steel liners make up the primary and secondary ducts. The primary duct provided cooling air for the reactor; the secondary duct maintained counter-flow cooling to prevent overheating of the concrete. The bottom of the air-plenum concrete is about 35 feet below the grade level. The main air duct has two expansion joints, which are believed to be potential points for the release of contamination from the ducts to the environment.

If it can be demonstrated that the soils under the air plenum are not contaminated above the established regulatory criteria or require

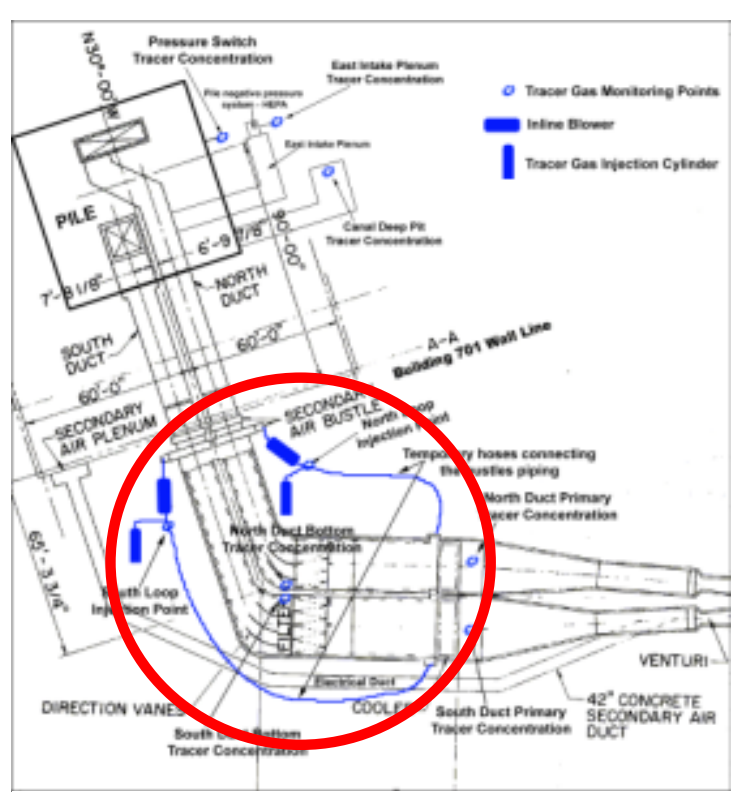

Figure 11 Schematic of the BGRR Showing the Below Grade Ducts only a small amount of remediation, the air plenums will not have to be removed. This will result in a substantial cost savings to the project of approximately $\$ 7 \mathrm{M}$ to $\$ 8 \mathrm{M}$. In addition, the milestone for completion of the BGRR Decommissioning Project is on the critical path for completing the BNL Environmental Restoration Program in 2006.

As part of the overall characterization efforts, the PFT technology was applied to determine gas leak pathways from the ducts. Contamination of soils was expected to coincide with the leak pathways out of the duct. Although every leakage location may 
not result in soil contamination (for example at the top of the duct), the likelihood of contamination occurring is highest in these areas. While the baseline characterization efforts emphasize the expansion joints, the PFT technology was used to determine more precisely and with higher confidence the areas where leakage occurred.

A more exact determination of leak pathways has several advantages. The use of PFTs determined which of the suspect areas were in fact leaking (and the relative magnitude of the leaks), but more importantly determined that no additional areas of the duct were leaking (e.g., significant cracks in the concrete duct). Another advantage to using PFTs was that they allowed elimination of some of the suspect contamination pathways by determining that they were not leaking. Exploratory type sampling was performed in these areas, saving considerable funds. Overall, the PFT technology allowed the regulators and stakeholders to have confidence in the sampling scheme that emphasized suspect/known leak pathways and used exploratory sampling elsewhere.

The PFTs were introduced into the interior volumes of the BGD through the secondary air system outer cooling channels. Monitoring wells were placed along both sides of the ductworks and topside along the central axis of each individual duct. A total of 42 wells with 140 sampling points were installed.

Two injection tests were performed. The first, termed the preliminary injection, was designed to determine the degree of leakage and cross-talk within the duct system and confirm the appropriate tracer gas flow rates. The second was the actual leak test, designed to determine the leak paths from the BGD. The North and the South Ducts were isolated from each other. Therefore, a different tracer was used in each cooling duct. This yielded data that was specific for each duct and helped to more accurately define leak pathways.

The PFTs were injected into the outer cooling channel of each BGD and distributed via a closed-loop circulation system. This allowed for recirculation of the tracer. The rate of gas injection was determined based on the volume of the cooling channel, the source concentration of the tracer (ranged from 100 to $1000 \mathrm{ppm}$ ), expected diffusion rates, and engineering assumptions about the cross-talk between the primary duct and reactor pile volumes with the secondary cooling ducts. Tracer injection rates ranged from $0.2 \mathrm{ml} / \mathrm{min}$ to $22 \mathrm{ml} / \mathrm{min}$. The target goal for the interior concentration was determined through modeling based on the flow rates, injection concentration and volume, and plenum volumes. The cooling channel PFT concentration was monitored at least daily during the duration of the injection and generally ranged from 10 to $100 \mathrm{ppb}$.

The data from the preliminary test showed transport to be fairly rapid. For this reason full sampling of the external ports was performed on alternating days starting 24 hours after injection began. Sampling continued for nine days at which time a consistent picture of the leak pathways from the ducts emerged, as judged through analysis of the data. The data interpretation was conducted with C Tech's EVS-PRO (5). EVS-PRO unites interpolation, geologic modeling, geostatistical analysis, and fully three- 
dimensional visualization tools into a software system developed to environmental contamination issues.

Figure 12 presents representative data for the tracer PMCP at the South Duct. Evidence of PMCP in the surrounding soils indicates a leak pathway from the internal duct. The diagram shows only the underground ducts and the sample locations. Sample concentrations are color coded with red denoting the highest concentration and blue the lowest. The red to orange areas near the bustle (left-hand side) indicate that a substantial hole exists in this area of the duct. Regions of minimal or no leakage are depicted in blue. The data clearly indicate that there are substantial areas where leakage is minimal. This would suggest soil characterization should be focused on the areas with the highest leak rates. If a region is not susceptible to gas leakage, it is not susceptible to water leakage.

\section{PMCP South Duct View February 14,2001}

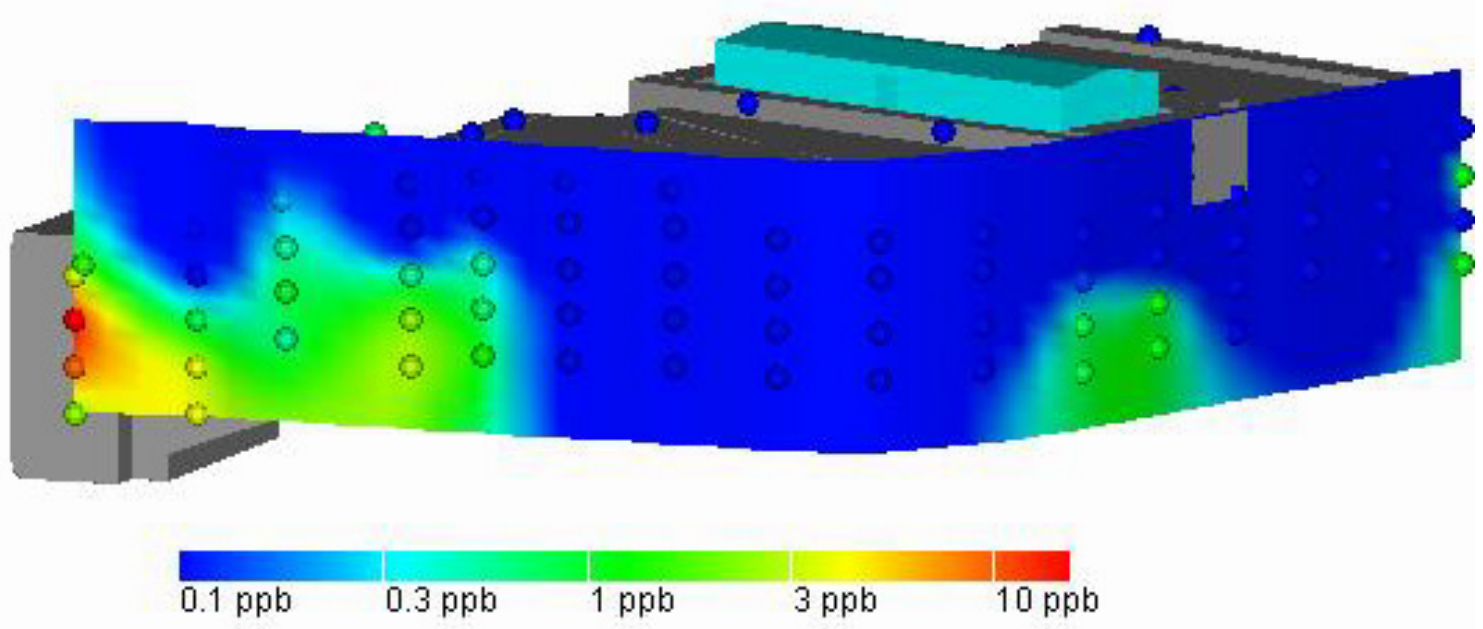

Figure 12 Concentration Profile for the Tracer PMCP at the South Duct

Figure 13 presents a representative data set for the tracer oPDCH at the North Duct on February $14^{\text {th }}$. There are several indications of leaks at this duct and the concentrations are typically higher than on the South Duct. The peak concentrations again indicate a substantially sized flaw in the duct allowing release of the gas. High values (green to red) were detected at the expansion joints on either side of the filter house and some at the bustle (green to cyan, right-hand side). 


\section{oPDCH North Duct View February 14, 2001}

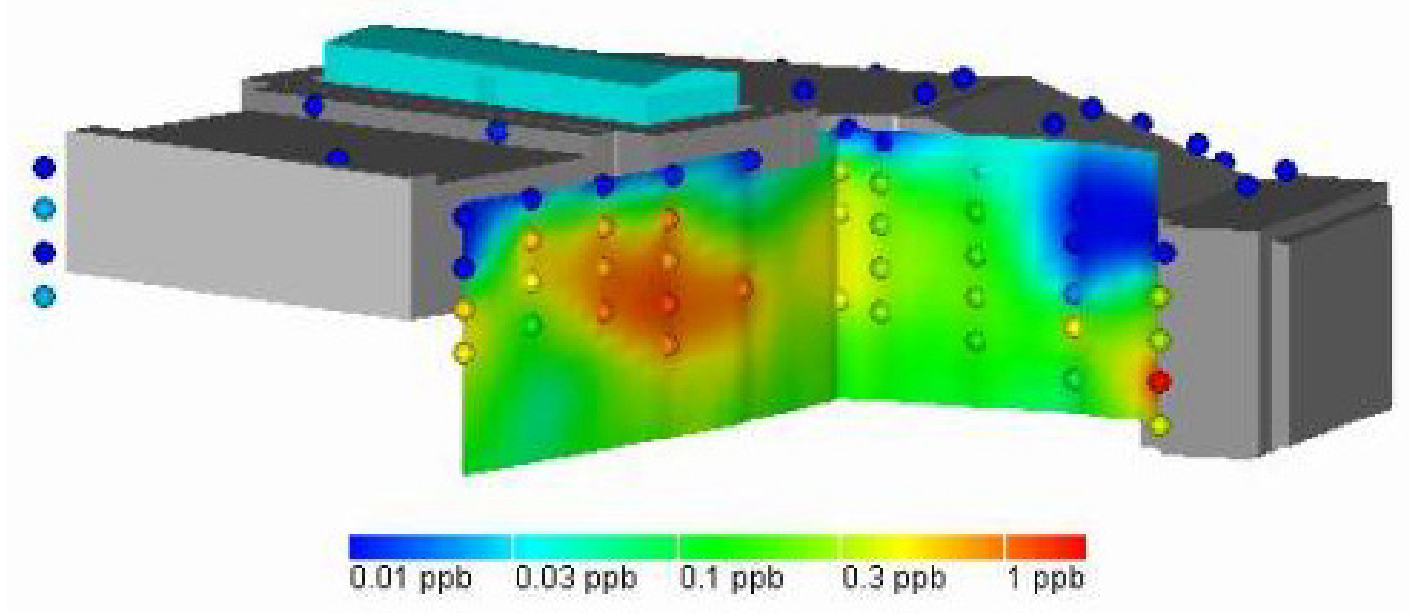

\section{Figure 13 Concentration Profile for the Tracer oPDCH at the North Duct}

The data analysis clearly indicates major leakage at the bustle area (nearest reactor building). Significant leaks are also seen near most of the expansion joints with greater leakage occurring on the north side. Much of the South Duct remains "clean" with only low concentrations of tracers present. The North Duct shows greater gas transport from the duct to the soil with high concentrations at each of the expansion joints.

The PFTs have allowed us to determine the leak paths and relative size of the leaks in the BGD without having to unearth and inspect the ducts. The information gained was used to guide the soil characterization.

\subsection{Cover Verification at the Savannah River Site Bentonite Mat Cover Test Facility}

\section{Key Successes}

- The proof-of-concept testing at Savannah River Site (SRS) was successful. The Bentomat Test Pad represented a worst-case scenario for tracer verification of covers. The cover had a very thin soil layer overlying the hydraulic barrier. This allowed barometric pumping, wind effects, and atmospheric dilution effects to be maximized.

- Three small (1 $\left.1 / 4^{\prime \prime}\right)$ flaws were readily detectable. Small flaws were detected without having to increase the internal concentrations of PFTs over normally used values

- The results were repeatable day-to-day and were confirmed by two separate tracers.

- The use of the field-deployable gas chromatograph PFT detector was successfully demonstrated. This unit was able to analyze samples on a four-minute cycle down to levels of a few parts per trillion 
With increased emphasis on site closures, cap and cover system verification and longterm monitoring has emerged as a leading and urgent issue. The transfer of the PFT technology from subsurface to surface barriers was a natural progression. The major issues associated with using the PFT technology with cap and cover systems is barometric pumping (dilution of tracers) and varying soil saturation (e.g., large-field changes after rainfall events or droughts).

The U.S. Department of Energy Environmental Management (DOE-EM) Program 2006 Accelerated Cleanup Plan is pushing for rapid closure of many of the DOE facilities. This will require a great number of new cover systems. Some of the se new covers are expected to maintain their performance for periods of up to 1000 years. In order for the cover to protect the environment it must remain free of holes and flaws throughout its service life. Covers are subject to subsidence, erosion, animal intrusion, plant root infiltration, etc., all of which will affect the overall performance of the cover. Long-term stewardship will require monitoring/verification of cover performance over the course of the designed lifetime. The need for a reliable method of verification and long-term monitoring is readily apparent.

Currently, failure is detected through monitoring wells downstream of the waste site. This is too late as the contaminants have already left the disposal area. Newly proposed monitoring methods measure temperature, moisture content, and other hydraulic parameters, which do not provide direct information on the potential for transport through the cover. Methods that indicate early cover failure (prior to contaminant release) or predict approaching cover failure are needed. BNL proposed using the PFT technology to verify and monitor cover performance. The PFTs are injected beneath the cover and monitored for above the cover (see Figure 14). The location, concentrations, and time of arrival of the tracer(s) provide a direct measure of cover performance. The PFT technology can verify that a cover meets all performance objectives upon installation, is capable of predicting changes in cover performance and failure before it happens, and can be cost-effective in supporting long-term stewardship needs. 


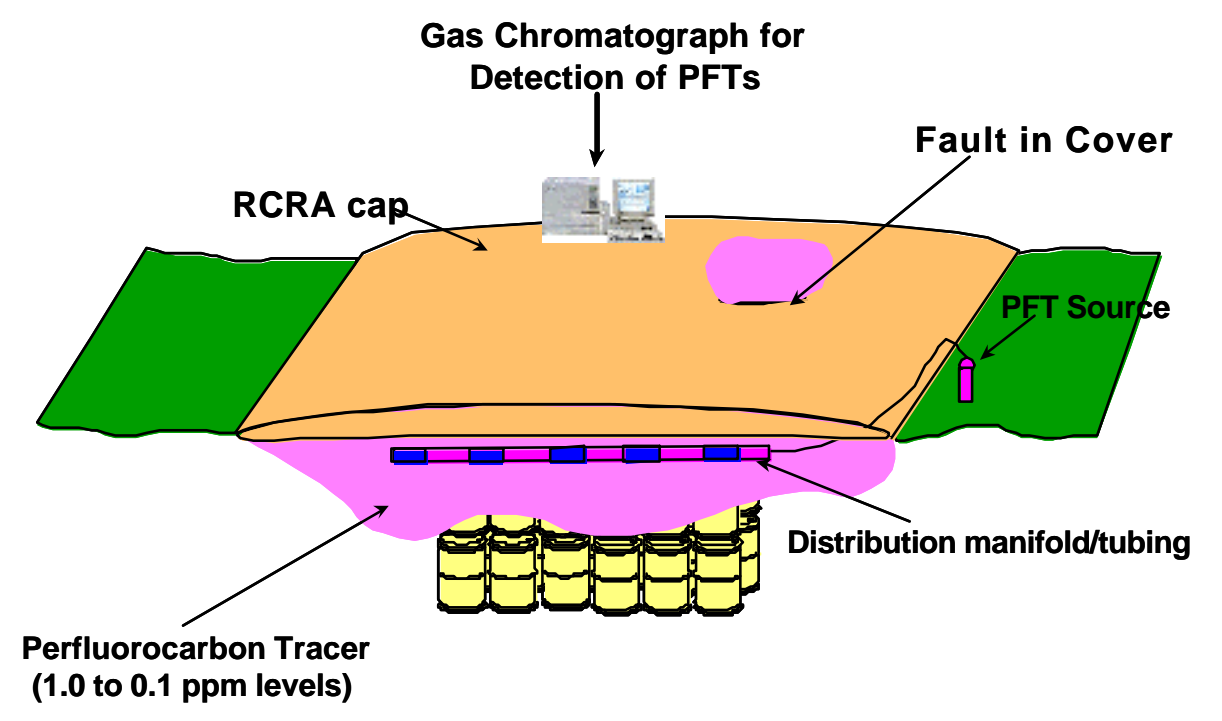

\section{Figure 14 Schematic of Brookhaven PFT Technology for Verification and Long- term Monitoring of Cap and Cover Systems}

The main objective of this program was to demonstrate, on a proof-of-concept level, that PFTs could be used to accurately and quickly locate flaws in a cover system. To this end, PFTs were used to verify the integrity of the part of the geosynthetic/geomembrame composite layer of the Bentomat Test Pad. This program was designed to address the barometric pumping issue but not other issues such as soil saturation. Barometric pumping was seen as the major obstacle to cover verification and monitoring. The other issues may affect the versatility or sensitivity of the technology, but not the basic operability of the technology.

The approach was to install tracer injection lines below the composite layer and monitor for the tracers in the soils above the layer. This was a very conservative test (aggressive test of the PFT technology) as the Bentomat Test Pad has only 1 to 2 feet of cover soil. This means that barometric pumping and dilution effects would be maximized. The tracers diffuse to the surface after only 2 feet of travel making horizontal travel minimal past the 2-foot boundary.

A secondary objective was to demonstrate a field-deployable PFT detection system. The system consisted of a dual-trap gas chromatograph and a compositing sampling approach (multiple soil-gas samples were combined and sampled as one composite).

The proof-of-concept test of the PFT technology utilized $60 \%$ of the top surface of the test pad. The remaining portion of the pad was left undisturbed for future evaluation of the pad. Monitoring ports were installed on top of the cover. A total of 84 sampling points were placed just above the HDPE geomembrane $(\sim 6 ")$ on five-foot spacing. Three tracers were used in the study. This allowed confirmatory data and also gave information on the interconnectivity of the subsurface below the composite layer (cavities did in fact interconnect and a fair degree of tracer mixing occurred). Three distinct regions of tracers were set up. In the southern most region $\mathrm{PMCH}$ tracer was injected at a rate of $12 \mathrm{~mL} / \mathrm{min}$ at a source concentration of $1600 \mathrm{ppm}$. The mid section had PMCP 
injected at $44 \mathrm{~mL} / \mathrm{min}$ with a source concentration of $400 \mathrm{ppm}$. The northern most region of the test region was injected with oc-PDCH at a flow of $53 \mathrm{~mL} / \mathrm{min}$ and $95 \mathrm{ppm}$ source concentration. The injection rates were set such that the internal concentrations beneath the hydraulic barrier would be between 1 and $10 \mathrm{ppm}$ after 5 to 7 days of injection. The injection spacing was approximately 15 feet between tracers.

The initial tracer injections were allowed to continue for six days prior to starting soil gas sampling. This allowed the site to reach a static condition. At this point soil gas sampling was initiated and all 84 sample ports were sampled on August $13^{\text {th }}$ and $14^{\text {th }}$

Samples were analyzed using a field-deployable gas chromatograph (GC). The instrument had dual traps for capturing the PFTs. This allowed individual sample analysis every four minutes. A sample size of $5 \mathrm{~mL}$ allowed detection down to $0.01 \mathrm{ppb}$ of the tracers. As the internal concentration goal was $1 \mathrm{ppm}$ this allowed for 5 orders of magnitude dilution across the geosynthetic liner/geomembrane and the 6" to 12 " of cover soil below the sample ports. From past experience, even small leaks on the order of $1 / 2$ " would be expected to have much less than 3 orders of magnitude dilution over this travel distance.

After the first two days of sampling and analysis, the data showed that the hydraulic barrier was intact. At this point three induced flaws were engineered into the cover. The flaws were placed in the front half of the grid to leave as much of the original cover "intact" as was reasonable. The flaws were introduced by simply driving a 1.25" diameter pipe into the subsurface a distance of four feet. The pipe was removed and the resulting hole was backfilled with fine sand. In two of the holes, sampling ports were also installed both above and below the geosynthetic liner. In one hole, $\mathrm{CH}-\mathrm{E}$, a subsidence cavity extending two feet below the Bentomat layer was found. These ports gave confirmation of internal tracer concentrations in areas well removed from the injection point.

On August 15 and 16 samples were taken at the sample ports surrounding the flaw locations. The 4 nearest neighbors to the flaws were sampled resulting in 12 samples taken each day. Samples were taken at random locations away from the flaws to provide confirmation that leaks were not present in other locations. As expected, leaks were not found away from the flaws.

The data was entered into a modeling software package, C-Tech's Environmental Visualization System (EVS-PRO). Figure 15 shows the plan and side views (side view has a vertical exaggeration of $10 \mathrm{X}$ for clarity) of the cover test grid with a color-coded mapping of tracer concentrations on August $13^{\text {th }}$. The side view includes tracer concentrations for both internals and externals. Blue areas represent low $(<0.01 \mathrm{ppb})$ tracer concentrations while pink areas are high concentrations $(\sim 1.0 \mathrm{ppm})$. Data visualizations for August $14^{\text {th }}$ were identical. While the internal volume of the cover clearly has high concentrations of PFTs the tracers are not reaching the external ports, which are approximately six inches above the Bentomat liner. The composite hydraulic 
barrier provided by the geosynthetic clay liner and HDPE membrane remained intact and leak-free.

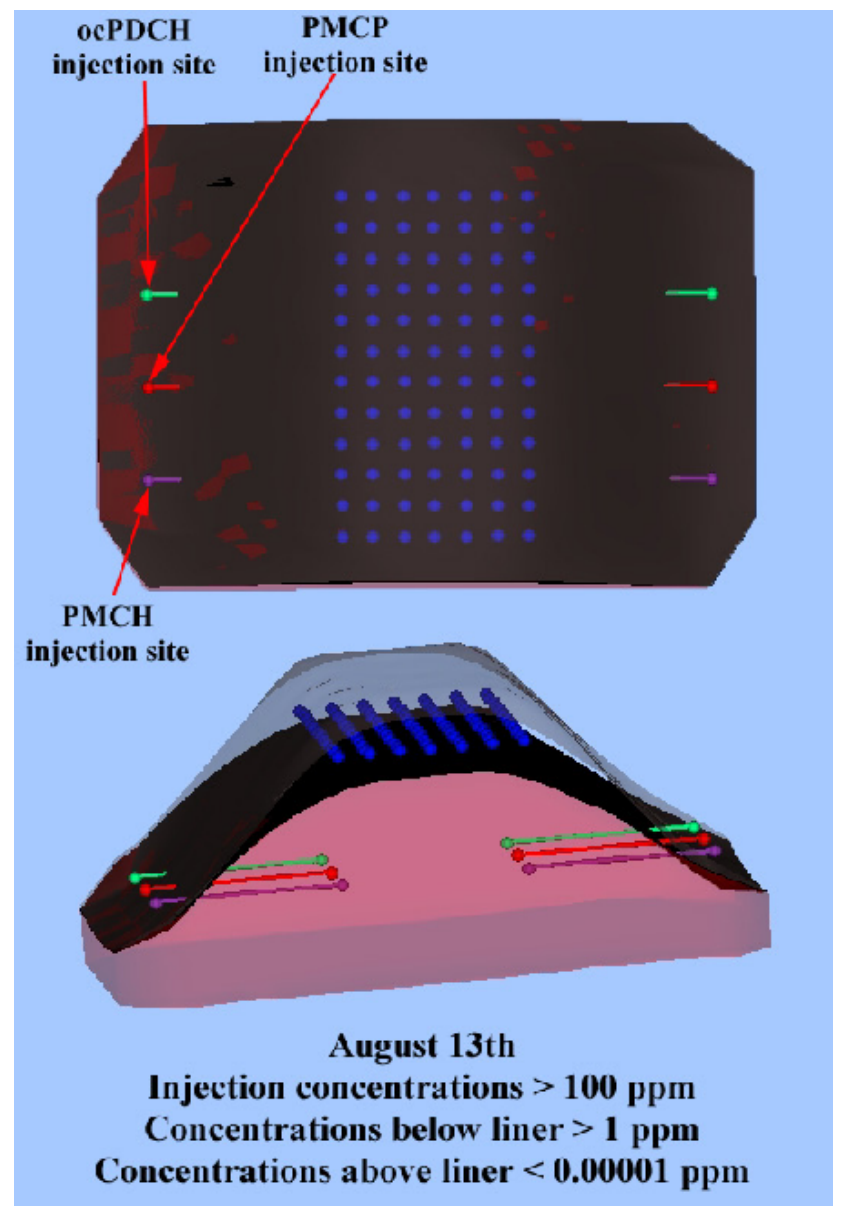

\section{Figure 15 Tracer Concentrations at the Bentomat Test Cover on August 13, 2001}

Modeling of diffusion of the gas through the Bentomat/HDPE layer indicated that the PFT diffusion coefficient through this layer was less than $10-8 \mathrm{~cm} 2$ /s. Higher diffusion coefficient values would have led to detection of PFTs at concentrations greater than 0.01 ppb. Based on previous work, the diffusion coefficient of PFTs in sandy soils is approximately $10-2 \mathrm{~cm} 2 / \mathrm{s}$, approximately 6 orders of magnitude greater than through the Bentomat/HDPE liner. This further supports the contention that the cover was not leaking.

On August 16 tracer levels beneath the Bentomat layer remained near $1 \mathrm{ppm}$. Analysis of the data showed all three flaws, with the nearest sample locations showing ppb levels of tracers (Figure 16). The ratio of $\mathrm{PMCH} / \mathrm{PMCP}$ in the cavity hole is similar to that seen in the monitoring network. Detection of PMCH and PMCP at the ports near the flaw gave confirmatory data that a leak existed. The data for the two tracers correlated well. Overall the concentration difference from internal (beneath the Bentomat liner) to external (above the Bentomat liner) was greater than seen in previous subsurface barrier 
testing and other deep, below-grade tracer studies. This is attributed to the low diffusion rate through the Bentomat/HDPE liner, barometric pumping, and higher diffusion coefficient in the sand backfilled flaw as compared to the native clay soil. As this is the most difficult cover system expected, in terms of thin surface cover, these data provide confidence that small flaws can be readily detected.

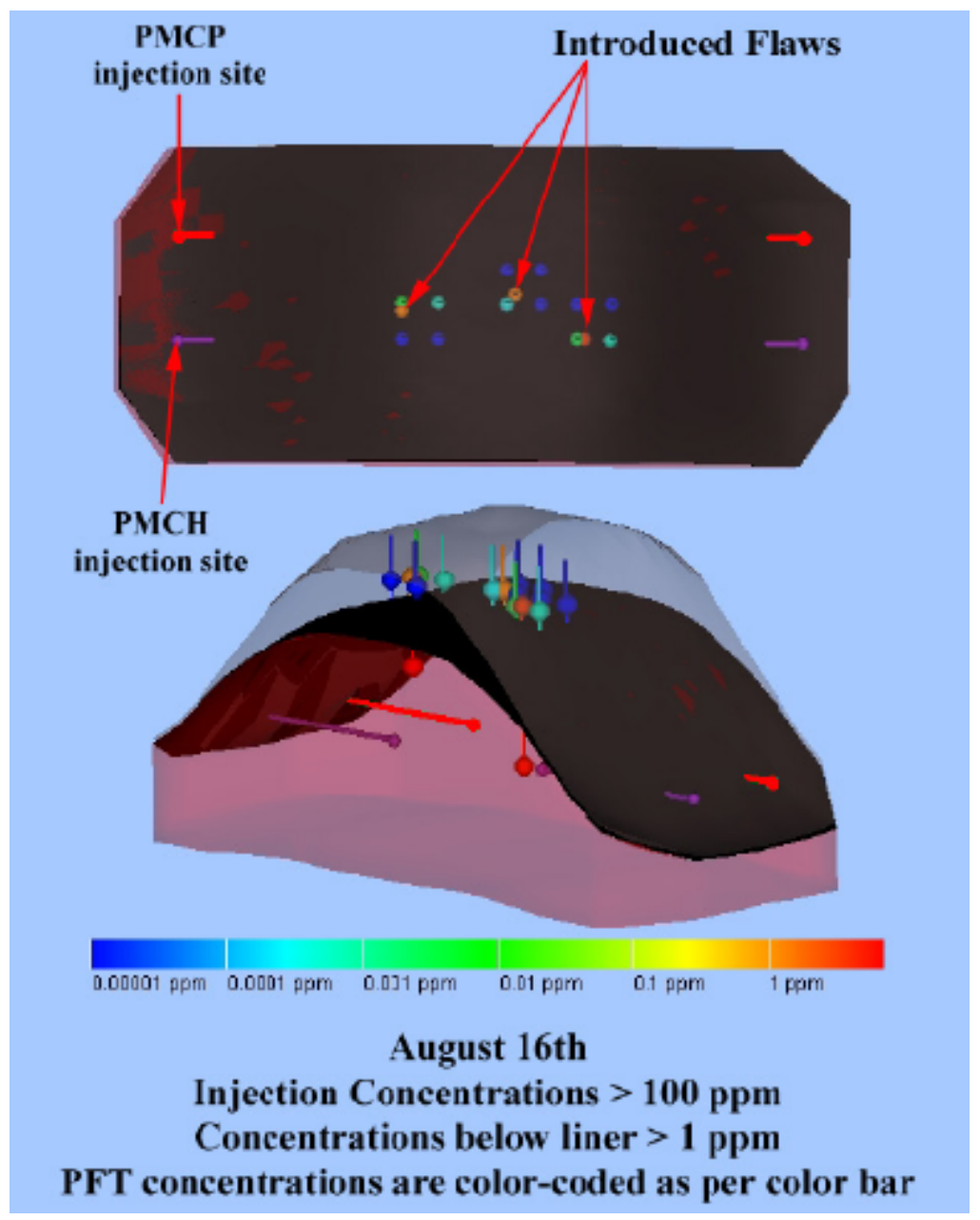

\section{Figure 16 PMCH Concentrations at the Bentomat Test Cover on August 16, 2001}

In addition, the use of the field-deployable gas chromatograph PFT detector was successfully demonstrated. This unit was able to analyze samples on a four-minute cycle down to levels of a few parts per trillion. This provided almost six orders of magnitude span between the concentrations beneath the liner ( $\mathrm{ppm}$ ) and non-detectable levels. This is more than sufficient to accurately determine the presence of a leak.

\subsubsection{Additional Benefits of using the PFT Technology for Cap and Cover Systems}

The multiple tracers available with PFTs (and not with competing systems) allow greater flexibility in experimental/installation design, yields redundant (re: confirmatory) data, and gives information on internal transport pathways not available from single tracer systems. This advantage is magnified when the PFT technology is applied to multi-layer 
cover systems. With multiple layers there may be convoluted leak pathways. Flaws in two layers may not be aligned and the transport pathway may have a horizontal aspect. In this case single tracer technology would see only the exit hole. Multiple tracers allow different tracers to be injected between layers. With monitoring ports placed within each layer it is easy to tell flaw location for each layer. Even having only monitoring ports above the final layer, the spectrum of tracers coming from an exit hole can be used to determine which layers are faulted and the concentrations can be used to estimate how convoluted the travel pathway is.

\subsection{Summary and Conclusions}

Currently, containment system failures are detected by monitoring wells downstream of the waste site. Clearly this approach is inefficient, as the contaminants will have migrated from the disposal area before they are detected. Methods that indicate early cover failure (prior to contaminant release) or predict impending cover failure are needed. The BNL PFT technology can measure performance changes and integrity losses as the cover ages. This allows early detection of cover failure or pending failure so that repair or replacement can be made before contaminants leave the disposal cell.

The PFT technology has been successfully applied to four subsurface barrier problems, one leak detection problem from underground ducts, and one surface cover problem. Testing has demonstrated that the PFTs are capable of accurately detecting and locating leaks down to fractions of an inch.

The PFT technology has several advantages over competing approaches. The ability to simultaneously use multiple PFTs separates it from other gas tracer technologies. Using multiple tracers provides independent confirmation of flaw location, helps to clearly define transport pathways, and can be used for confirmatory testing (e.g., repeat the test using a new tracer). The PFT tests provide a direct measure of flaws in a barrier, whereas other measurements (pressure, moisture content, temperature, subsidence) provide indirect measures that need interpretation.

The focus of the six PFT demonstrations has been on engineering aspects of the technology with the intent of finding if a flaw existed in the barrier. Work remains to be done on the scientific basis for this technology. This includes determining PFT diffusion rates through various materials (soils and barrier) as a function of moisture content, determining the effects of barometric pumping on PFT flow for cover systems, and determining wind effects on side slopes of cover systems and their impact on PFT performance. It also includes application of models to assist in the design of the monitoring system and the interpretation of the data.

The set of demonstrations was performed on small sites $(<1 / 4$ acre $)$. Future work also needs to consider scaling issues to develop and design optimal techniques for delivery and monitoring of the PFTs. 
The PFT technology directly supports accelerated site closure needs outlined under Thrust I as recently defined by DOE EM-1. Fernald, Rocky Flats, and all of the smaller closure sites are planning to use some form of barrier to contain contaminants. Some of these new covers are expected to maintain their performance for periods of up to 1000 years. The need for a reliable method of verification and long-term monitoring is readily apparent. The BNL PFT technology can uniquely fulfill many aspects of verification and long-term monitoring.

\subsection{References}

1. Heiser, J.H. and Sullivan, T.M., "Using Perfluorocarbon Tracers for Verification of Cap and Cover Systems Performance", Brookhaven National Laboratory, Upton, New York, November 2001, BNL-52647.

2. Heiser, J.H., Serrato, M., and Sullivan, T.M., "Proof-of-Concept Test of a Unique Gaseous Perfluorocarbon Tracer System for Verification and Long-term Monitoring of Caps and Cover Systems Conducted at the Savannah River Site Bentonite Mat Test Facility", Waste Management '02, February 2002, Tucson, AZ.

3. Heiser, J.H., Sullivan, T.M., Kalb, P.D., Milian, L., Wilke, R., Newson,C., and Lilimpakis, M., "Characterization of Leak Pathways in the Below Grade Ducts of the Brookhaven Graphite Research Reactor Using Perfluorocarbon Tracers", Brookhaven National Laboratory, Upton, New York, April 2001, BNL-52629

4. Heiser, J.H., Sullivan, T.M., Milian, L., Wilke, R., Newson,C., and Lilimpakis, M., 'Using Gaseous Perfluorocarbon Tracers to Characterize Leak Pathways in the Below Grade Ducts of the Brookhaven Graphite Research Reactor", Waste Management '01, February 2001, Tucson, AZ.

5. Sullivan, T.M., Heiser, J.H., Senum, G., and Milian, L., 'Use of Perfluorocarbon Tracer (PFT) Technology For Subsurface Barrier Integrity Verification at the Waldo Test Site", Waste Management '00, February 2000, Tucson, AZ.

6. Heiser, J. and Dwyer, B.P., "Summary Report on Close-Coupled Subsurface Barrier Technology - Initial Field Trials to Full-Scale Demonstration", Brookhaven National Laboratory, Upton, New York, September 1997, BNL-52531.

7. Sullivan, T.M., Heiser, J., Gard, A., and Senum, G., "Monitoring Subsurface Barrier Integrity Using Perfluorocarbon Tracers", ASCE Journal of Environmental Engineering, Vol. 124, No. 6, 1998.

8. D’Ottavio, T.W. and Dietz, R.N., "Radon Source Rate Measurements using Perfluorocarbon Tracers", Indoor Air '87, 4th International Conference on Indoor Air Quality and Climate, Berlin, Germany, 1987. 
9. Horn, E.G., Dietz, R.N., Aldous, R.M., Leadon, G.A., Honan, J.J., and Seiffert, K.K., EPRI 1991 PCB Seminar, Baltimore, MD, Electric Power Research Institute, 1991.

10. Sullivan, T., Armstrong, A.Q., Dindal, A.B., Jenkins, R.A., Osleeb, J., and Koglin, E.N., "Environmental Technology Verification Report. Environmental Decision Support Software. C Tech Development Corporation, Environmental Visualization System (EVS)," EPA/600/R-00/047, 2000.

11. Deitz, R.N., "Perfluorocarbon Tracer Technology, Regional and Long-Range Transport of Air Pollution," Elsevier Science Publishers, B.V. Amsterdam, The Netherlands, 215-247.

12. Dunn, S.D., Lowry, W., Chipman, V., and Sullivan, T., "Draft Phase II Test Plan for the Gaseous Tracer Comparative Tests Conducted at the Waldo Subscale Barrier Test Facility”, SEA-SF-TR-98, October 1998.

13. Serrato, M.G., "Bentonite Mat Demonstration, Final Report," Westinghouse Savannah River Company, Aiken, SC, December 1994, WSRC-TR-94-0618. 